\title{
Sunflower Protein Precipitation in a Tubular Precipitator
}

\author{
MATHEO RAPHAEL and SOHRAB ROHANI
}

\author{
Department of Chemical Engineering, University of Saskatchewan, Saskatoon, SK S7N 5C9, Canada
}

\begin{abstract}
Isoelectric precipitation of sunflower protein was carried out in a $20 \mathrm{~m}$ long, $6 \mathrm{~mm}$ internal diameter glass tubular precipitator. Effects of feed flow rate, protein concentration in the feed stream, and mean residence time on particle size distribution (PSD) were studied. The population balance equation (PBE) for the tubular precipitator was solved using the orthogonal collocation multiple shooting method. A simulated annealing method was used to determine the precipitation kinetic parameters for the nucleation rate, growth rate, aggregation rate, and breakage rate from the experimental data. Due to the lack of experimental data on the kinetics of sunflower protein precipitation in the literature, the extracted kinetics from our experiments were used to evaluate the predictive capability of the present model for experiments whose results had not been used to derive the kinetics. The model predictions of the particle size distribution along the tubular precipitator showed better agreement with the experimental data for large particles in comparison to the small particles $(<10 \mu \mathrm{m})$
\end{abstract}

On a effectué la précipitation isoélectrique de la protéine de tournesol dans un précipitateur tubulaire en verre de $20 \mathrm{~m}$ de long et $6 \mathrm{~mm}$ de diamètre intérieur. Les effets du débit de l'alimentation, de la concentration en protéine dans le courant d'alimentation et du temps de séjour moyen sur la distribution de taille des particules (PSD) ont été étudiés. L'équation de bilan de populations (PBE) pour le précipitateur tubulaire a été résolue à l'aide d'une méthode de type collocation orthogonale à tirs multiples. On a employé une méthode de recuit simulée pour déterminer les apramètres de la cinétique de précipitation pour la vitesse de nucléation, le taux de croissance, le taux d'agrégation et la vitesse de rupture à partir des données expérimentales. En raison de l'absence de données expérimentales sur la cinétique de précipitation de la protéine de tournesol dans la littérature scientifique, on a utilisé les cinétiques issues de nos expériences afin d'évaluer la capacité prédictive du présent modèle pour des expériences dont les résultats n'ont pas été utilisés pour le calcul des cinétiques. Les prédictions du modèle de la distribution de taille des particules le long du précipitateur tubulaire montrent un meilleur accord avec les données expérimentales pour des particules larges comparativement aux petites particules $(<10 \mu \mathrm{m})$.

Keywords: isoelectric precipitation, tubular precipitator, precipitation kinetics, population balance.

$\mathrm{D}$ efatted oilseed meals are known to contain large amounts of nutritional proteins, which can be recovered for use in food and pharmaceutical industries. Protein recovery from solution is often achieved through precipitation, followed by solid-liquid separation. The efficiency of the subsequent processes in solids protein recovery, i.e. sedimentation or centrifugation and spray drying, depend on the size of the particles and their strength to withstand the hydrodynamic shear. To minimize losses of the solids, it is essential to maximize the mean particle size and the particle strength and minimize the spread of particle size distribution (PSD).

Studies on isoelectric precipitation of oil seeds proteins have been done by several workers using different types of precipitators. Studies on batch precipitators have been reported by: Virkar et al. (1982), Petenate and Glatz (1983a and 1983b), Twineham et al. (1984), Nelson and Glatz (1985), Brown and Glatz (1987), and Chen and Rohani (1992). Grabenbauer and Glatz (1981), Glatz et al. (1986), Rohani and Chen (1993), and Raphael and Rohani (1996a) have used mixed suspension mixed product removal precipitators (MSMPRP). Only three studies have been reported on tubular precipitators: Virkar et al. (1982), Chan et al. (1986), and Raphael et al. (1995).

Previous studies on protein precipitation (Virkar et al., 1982; Grabenbauer and Glatz, 1981; Petenate and Glatz, 1983a and 1983b; Glatz et al., 1986), including the present study, have shown that, protein particles can exhibit a unimodal or bimodal PSD in population density depending on

*Author to whom correspondence should be addressed. E-mail address: rohani(wengr.usask.ca the type of the precipitator and the operating conditions used. The presence of large aggregates together with smaller aggregates and primary particles may result in a bimodal PSD. In such a system, determination of kinetic parameters is difficult, because the number of particles changes fast, due to aggregation and large particles cannot be distinguished from aggregates.

Virkar et al. (1982) studied the isoelectric precipitation of soy protein in a tubular precipitator under turbulent flow regime. The flow Reynolds number used was greater than 20000 , with the flow of protein solution being much greater than that of the acid. The authors modeled the growth of protein particles along the tubular precipitator using the Smoluchowski's theory. They assumed that the particle growth is by orthokinetic aggregation of particles caused by particle particle collision in the turbulent flow regime. That is, for two particles of radius $r_{i}$ and $r_{j}$ the frequency of orthokinetic collision per unit volume in turbulent shear flow is given by:

$$
F_{i j}=\frac{4}{3}\left(r_{i}+r_{j}\right)^{3} N_{i} N_{j}\left(\frac{\eta}{v}\right)^{1 / 2}\left(1-\frac{\delta_{i j}}{2}\right) \ldots \ldots \ldots
$$

where the energy dissipation per unit mass was defined as; $\eta=2 f \rho v_{L}^{3 / d} d_{t}$. For effective collision leading to a lasting aggregation, the radius of a newly formed aggregate was assumed to be less than $r_{\max }(30 \mu \mathrm{m})$ otherwise the collision was ineffective. That is:

$$
\begin{aligned}
& \left(r_{i}^{3}+r_{j}^{3}\right)^{1 / 3}>r_{\text {max }}, \Lambda_{i, j}=0 \quad \text { ineffective collision. } \\
& \left(r_{i}^{3}+r_{j}^{3}\right)^{1 / 3} \leq r_{\max }, \Lambda_{i, j}=1 \quad \text { effective collision } . .
\end{aligned}
$$


The model results showed good predictions between the calculated and experimental mean particle sizes for the initial stages (at the start). As the mean residence time (growth time) increased the calculated mean size was much larger than the experimental data. This was attributed to the lack of a proper model for the breakage of the larger aggregates (formed by the collisions that resulted in particles larger than $r_{m a x}$, and due to the exclusion of the precipitation kinetics: nucleation and particle growth rates.

Virkar and co-authors considered the tubular precipitator as an aggregator with a limited particle breakage. Also, the assumption that the precipitation process is a very fast reaction and is almost complete within $1 \mathrm{~s}$, neglects the molecular particle growth by diffusion which may continue beyond I $\mathrm{s}$. This is because the diffusion process is a slow process and depends on the mixing of the suspension. Thus, the particle growth may continue for some time before the concentration gradient vanishes, although the contribution in the particle size change by the growth mechanism may be much smaller when compared to that caused by the aggregation mechanism.

Chan et al. (1986) studied the kinetics of soy protein in a tubular precipitator using different precipitants. Experiments were carried out in the laminar flow regime $(R e=500$, based on total feed flow rate). In their study, no attempt was made to determine the precipitation kinetics, or to model the PSD for the tubular precipitator. They also reported that, for high concentrations of protein solutions, the solid protein comes out of the solution within $1 \mathrm{~s}$. The initial primary particles grow by aggregation and their final size depends on the growth and breakage rates controlled by shear forces and the type of the precipitant used.

In another study, Rivera and Randolph (1978) studied the continuous precipitation of pentaerythritol tetranitrate (TNT) in a short tubular precipitator. The precipitator was assumed to operate in the dispersed plug flow regime $(P e=51)$ with no particle aggregation or breakage. The $\mathrm{PBE}$ was given as:

$$
D_{z} \frac{\partial^{2} p}{\partial z^{2}}=u_{z} \frac{\partial p}{\partial z}+G \frac{\partial p}{\partial L}
$$

The PBE was solved using the method of moments. The nucleation rate $\left(B^{\circ}\right)$ and the growth rate $(G)$ along the tubular precipitator were assumed to be functions of the initial values: $B^{o}=B^{o}(1-z)^{a}$ and $G=G^{\alpha}(1-z)^{b}$. A similar method was used by Raphael et al. (1995), for determination of the precipitation kinetic parameters for the sunflower protein from the tubular precipitator (using the data in the dispersion region). In their study, the deconvolution of moments to generate the PSD using the matrix inversion method suggested by Randolph and Larson (1988) was not successful. Instead, a method suggested by Hulburt and Katz (1964) using gamma weighted Laguerre polynomials was used.

In the present study, a full model incorporating primary nucleation, molecular particle growth, particle aggregation, particle breakage, and flow dispersion along the tubular precipitator is being used. The experimental data from the tubular and batch precipitators at known conditions were used to obtain the kinetic parameters by optimization technique. Given the operating parameters: protein feed concentration, feed flow rate, dispersion rate, and particle size distribution at known locations after the mixing zone, predictions of the PSD and solids yield of sunflower protein (during precipitation at isoelectric $\mathrm{pH}$ using aqueous $\mathrm{HCl}$ solution) along the tubular precipitator can be calculated.
TABLE I

Solution Methods of the PBE and Some of Their References

\begin{tabular}{|c|c|}
\hline Solution Method & Reference \\
\hline Inverse transformation & Saleeby and Lee (1994) \\
\hline $\begin{array}{l}\text { Method of moments with } \\
\text { Laguerre polynomials }\end{array}$ & Hurburt and Katz (1964) \\
\hline $\begin{array}{l}\text { Method of moments with } \\
\text { matrix inversion }\end{array}$ & Randolph and Larson (1988) \\
\hline $\begin{array}{l}\text { MWR with Laguerre } \\
\text { polynomials }\end{array}$ & $\begin{array}{l}\text { Subramanian and Ramkrishna } \\
\text { (1971) }\end{array}$ \\
\hline $\begin{array}{l}\text { MWR with problem specific } \\
\text { polynomials (PSP) }\end{array}$ & $\begin{array}{l}\text { Singh and Ramkrishna } \\
\text { (1975 and 1977) }\end{array}$ \\
\hline $\begin{array}{l}\text { MWR with variable } \\
\text { collocation points }\end{array}$ & Sampson and Ramkrishna (1985) \\
\hline $\begin{array}{l}\text { MWR with shifted Legendre } \\
\text { functions }\end{array}$ & Chang and Wang (1984) \\
\hline MWR & Witkowski and Rawlings (1987) \\
\hline $\begin{array}{l}\text { Galerkins and orthogonal } \\
\text { collocation }\end{array}$ & Rawlings et al. (1992) \\
\hline Orthogonal collocation & Lakatos et al. (1984) \\
\hline $\begin{array}{l}\text { MWR with fractional } \\
\text { moments }\end{array}$ & Bhatia and Chakraborty (1992) \\
\hline Method of classes & Machall et al. (1988) \\
\hline Stochastic method & Gupta and Dutta (1990) \\
\hline \multirow{5}{*}{$\begin{array}{l}\text { Finite differences } \\
\text { (discretization) method }\end{array}$} & Hounslow et al. (1988) \\
\hline & Hounslow (1990a) \\
\hline & Hounslow (1990b) \\
\hline & Kimand Tarbell (1991) \\
\hline & Lister et al. (1995) \\
\hline
\end{tabular}

\section{Methods of solving the population balance equation (PBE)}

In order to determine the precipitation kinetics (from experimental data), it is necessary to represent the system using the population balance equation (PBE). The population balance equations for crystallization and precipitation processes in the batch precipitator and mixed-stirred precipitators have been solved by several workers. The solution methods can be categorized into six main groups: analytical method, method of moments, method of weighted residue (MWR), method of classes, stochastic method, and finite difference (discretization) method. Table 1 presents a summary of the these methods.

For a simple linear PBE, Laplace transformation or inverse transformation has been used to give an approximate solution. Saleeby and Lee (1994) solved analytically the PBE for an MSMPR crystallizer with agglomeration. When nonlinear terms (aggregation or breakage) are included in the PBE, solution by analytical method becomes difficult.

Hurburt and Katz (1964) formulated the number density balance equation for continuous flow systems using a classical statistical mechanics method. They suggested an analytical method of moments for solving the balance equation, then gamma weighted Laguerre polynomials were used to reconstruct the PSD from the moments. This deconvolution method has been reported to result in strong oscillations of the PBE (Randolph and Larson, 1988). Instead, Randolph and Larson (1988) proposed the matrix inversion method. In this method, the moments equations are transformed into linear algebraic equations and solved numerically.

The method of moments developed by Randolph and Larson (1988), is widely used to solve PBE for MSMPR precipitators. The method transforms the difficult to solve integro-differential equation into a set of ordinary differential equations by 


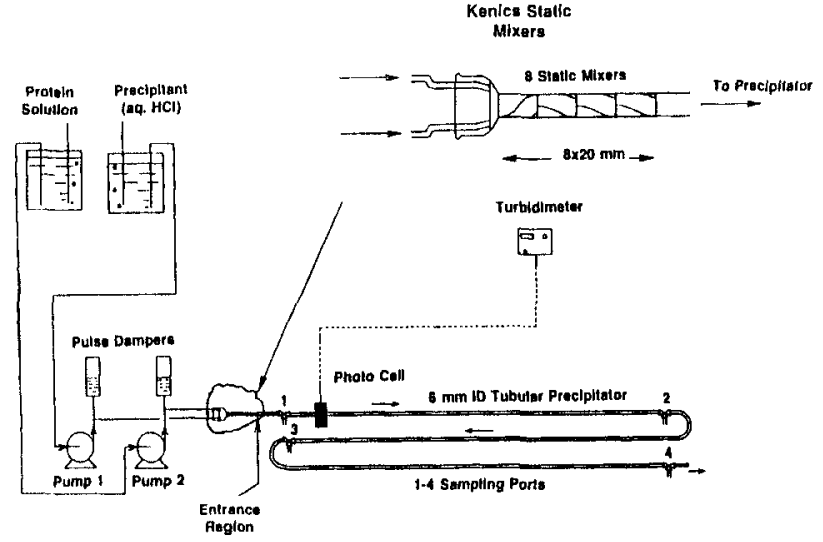

Figure 1 - Experimental setup of the tubular precipitator.

moment method. The drawback of this method lies in the deconvolution of the moments to yield the PSD, sometimes convergence to the final solution is not achieved, resulting in positive and negative number population densities (Kim and Tarbell, 1991 and Raphael et al., 1995).

The method of weighted residue (MWR), after Finlayson (1972), has been used to solve the PBE by several workers. The method involves expanding the unknown solution using a combination of known trial functions (Laguerre Polynomial, shifted Legendre polynomials, or problem specific polynomials) and substituting into the original equation. The satisfying solution is obtained when the residual is zero, or close to zero. This is achieved by orthogonalizing the residual with a set of weighting functions. The difficult part of this method is in identifying the form of the trial function which represents the solution in the whole range. Orthogonal Collocation is a special form of MWR, in that the resulting residual is set to zero at fixed node points.

Padia and Bhatia (1991) analyzed the stability of the precipitation systems resulting from the coupling of the material balance equation, PBE, and kinetic equations for nucleation and growth rates. They stated that the solution of these coupled equation exhibit the multiple steady states when certain ranges of kinetic parameters are used. Similar observations have been reported by Witkowski and Rawlings (1987) and Tavare and Garside (1985).

In the current study, the orthogonal collocation method was used to solve the PBE in the particle size direction and multiple shooting method in the flow direction. The exponentially weighted Laguerre polynomial was used as a trial solution.

\section{Experimental method}

In this study, experiments on isoelectric precipitation of sunflower protein were carried out in a tubular precipitator. The effects of flow velocity, mean residence time, and protein feed concentrations on PSD were studied. The tubular precipitator consisted of a horizontal $20 \mathrm{~m}$ long, $6 \mathrm{~mm}$ inner diameter glass tube, having four $20 \times 11 \mathrm{~mm}$ Kenics static mixers (Koch Engineering Co. Inc., Wichita, KA) at the entrance and 4 sampling ports located at $0.4,3.3,9.5$, and $20.1 \mathrm{~m}$ from the entrance (Figure 1). The flow rates in the tubular precipitator were set to correspond to flow $R e=800$ or $R e=5000$, based on the total feed flow rates (see Table 2).

The axial dispersion number in the tubular precipitator was determined in terms of Peclet number $(P e=u \cdot z / D)$ using the residence time distribution (RTD) method. Pulse
TABLE 2

List of the Experimental Runs Performed in the Tubular Precipitator

\begin{tabular}{ccc}
\hline Run No. & Flow Re No. & $\begin{array}{c}\text { Protein feed conc. } \\
\left(\mathrm{kg} / \mathrm{m}^{3}\right)\end{array}$ \\
\hline L1 & 800 & 11.8 \\
L2 & 5000 & 11.8 \\
L5 & 800 & 11.8 \\
L6 & 5000 & 2.8 \\
L7 & 5000 & 2.8 \\
I1 & 3000 & 11.4 \\
I2 & 3000 & 11.6 \\
I4 & 5000 & 7.1 \\
\hline
\end{tabular}

response from a non-reactive tracer (aqueous $\mathrm{KCl}$ ) was used for this study at different flow velocities, Levenspiel (1972). The resulting best fit equation was given by:

$$
\frac{1}{P e}=0.0263-0.00015 u_{z}
$$

where $u_{z}(\mathrm{~cm} / \mathrm{s})$ is the superficial liquid flow velocity and the coefficient of regression, $R^{2}=0.905$. The range of the flow velocity covered both laminar and turbulent flow regimes. The dispersion number was assumed to remain constant along the length of the tubular precipitator at a given flow velocity. According to Nauman and Buffham (1983), the axial dispersion model can be used to approximate the laminar flow systems, even though the flow velocity profiles are not flat. In the present work, the dispersion coefficient $D$. combines the effect of laminar velocity profiles and the molecular diffusion (Taylor-Aris dispersion). This is valid for long tubes with small ratio of $d_{t} / z_{T}$.

For all experiments, the protein feed solution was extracted from defatted seeds (prepared from confectionery-type sunflower seeds) using aqueous solution $(1: 20 \mathrm{~g} / \mathrm{mL})$ at $\mathrm{pH} 10$. Precipitation was carried out at $22 \pm 2^{\circ} \mathrm{C}$ at $\mathrm{pH} 4$ (isoelectric $\mathrm{pH}$ ) by contacting equal volumes of protein solution with aqueous $\mathrm{HCl}$ solution. The concentration of protein in the feed solution was maintained at 2.8 or $11.8 \mathrm{~kg} / \mathrm{m}^{3}$, while the concentration of aqueous $\mathrm{HCl}$ solution was predetermined by titration (in order to achieve a final solution $\mathrm{pH}$ of 4 ). A total of four experiments with replications were performed Two more runs were carried out, one at an intermediate flow Reynolds number $(R e=3000)$ and the other at an intermediate protein concentration $\left(7.1 \mathrm{~kg} / \mathrm{m}^{3}\right)$.

In a separate study, batch precipitation experiments were performed to determine the final concentration of protein in the solution $\left(C^{*}\right)$ after precipitation (using equal volumes of protein solution and aqueous $\mathrm{HCl}$ at temperature rango between 295 and $318 \mathrm{~K}$ ). The final protein concentration was found to be related to the precipitation temperature $\left(I_{n}\right.$ in $\mathrm{K}$ ) and the initial concentration of protein $\left(C_{0}\right)$ by:

$$
\begin{aligned}
& C^{*}=K_{s} \frac{C_{0}}{2} \ldots \\
& K_{s}=k_{0} e^{-k_{E R^{\prime}} T p} .
\end{aligned}
$$

Equations (3b) and (3c) were fitted to the experimental data using least squares error method (SAS manual, 1985). The optimized parameters obtained were: $k_{0}=0.785$ and $k_{t R}$ $=247.6 \mathrm{~K}$ with $R^{2}=0.992$. 


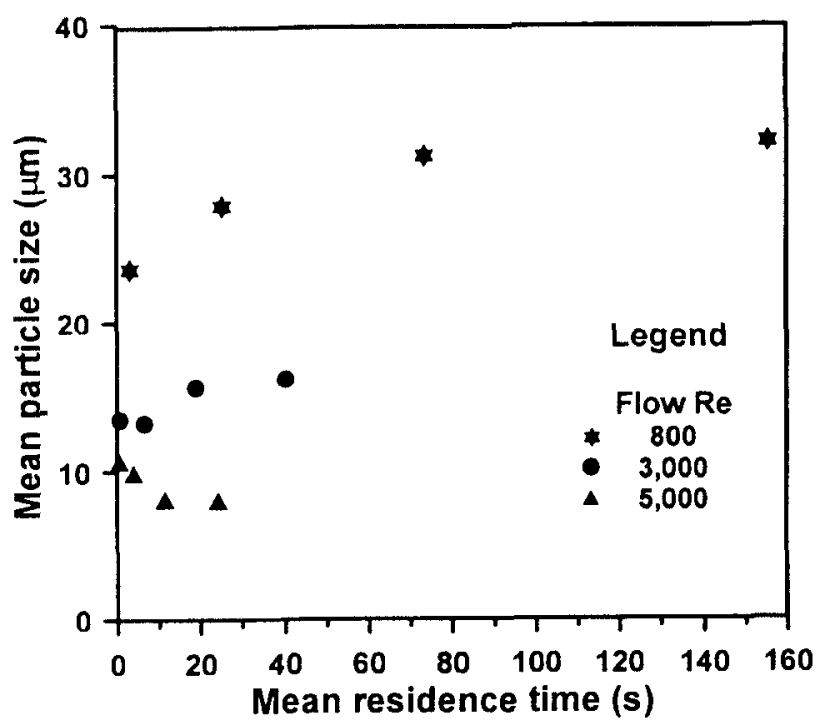

Figure 2 - Effect of flow Reynolds number on the mean particle size: feed ratio $=1.0 \mathrm{v} / \mathrm{v}$ (aqueous $\mathrm{HCl}$; protein solution) and protein feed concentration $=11.8 \mathrm{~kg} / \mathrm{m}^{3}$.
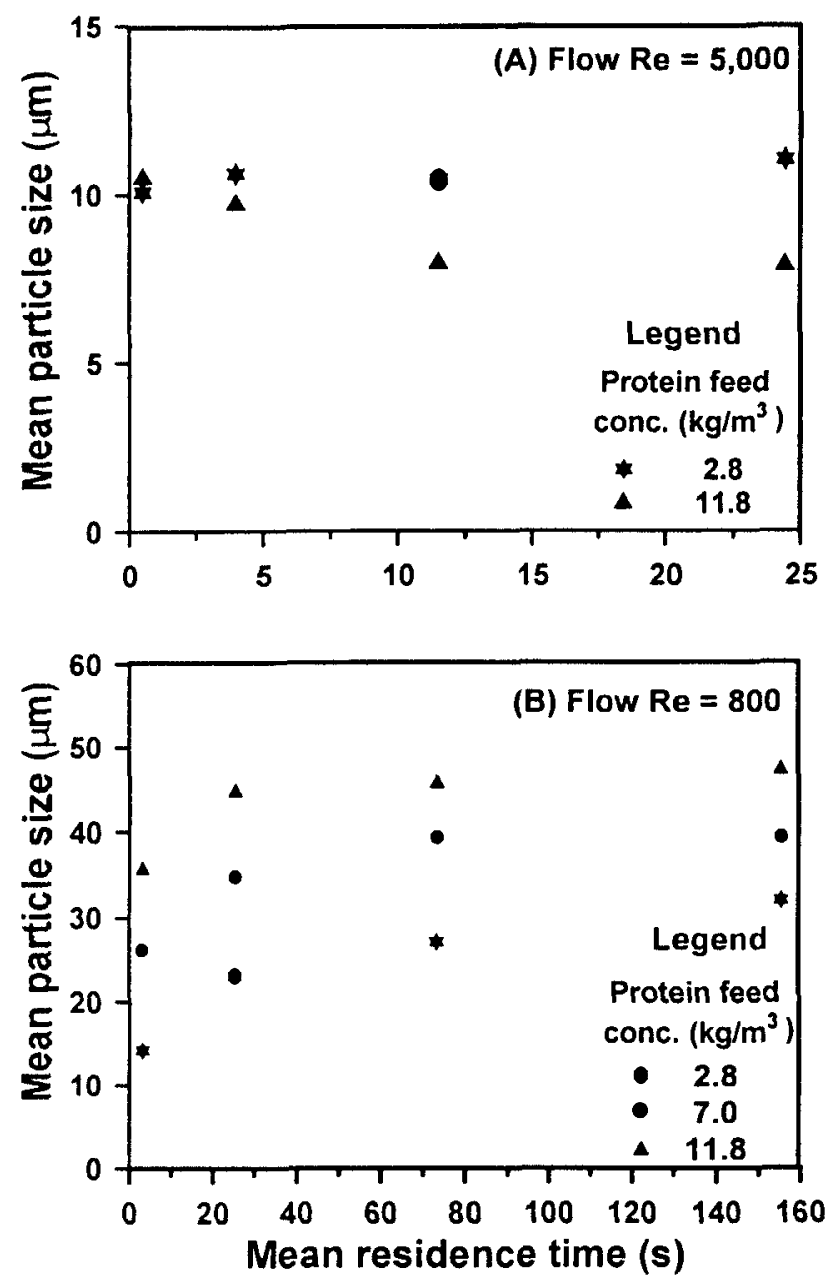

Figure 3 - Effect of protein feed concentration on the mean particle size: A) total flow $\operatorname{Re}=5000$, B) total flow $\operatorname{Re}=800$, feed ratio $=1.0 \mathrm{v} / \mathrm{v}$ (aqueous $\mathrm{HCl}$; protein solution), and protein feed concentration $=11.8 \mathrm{~kg} / \mathrm{m}^{3}$.

The PSD of the precipitate was obtained using a Coulter counter (model TAII, Coulter Electronics, Inc., Hialeah, FL). The solids protein concentration was measured using an on-line
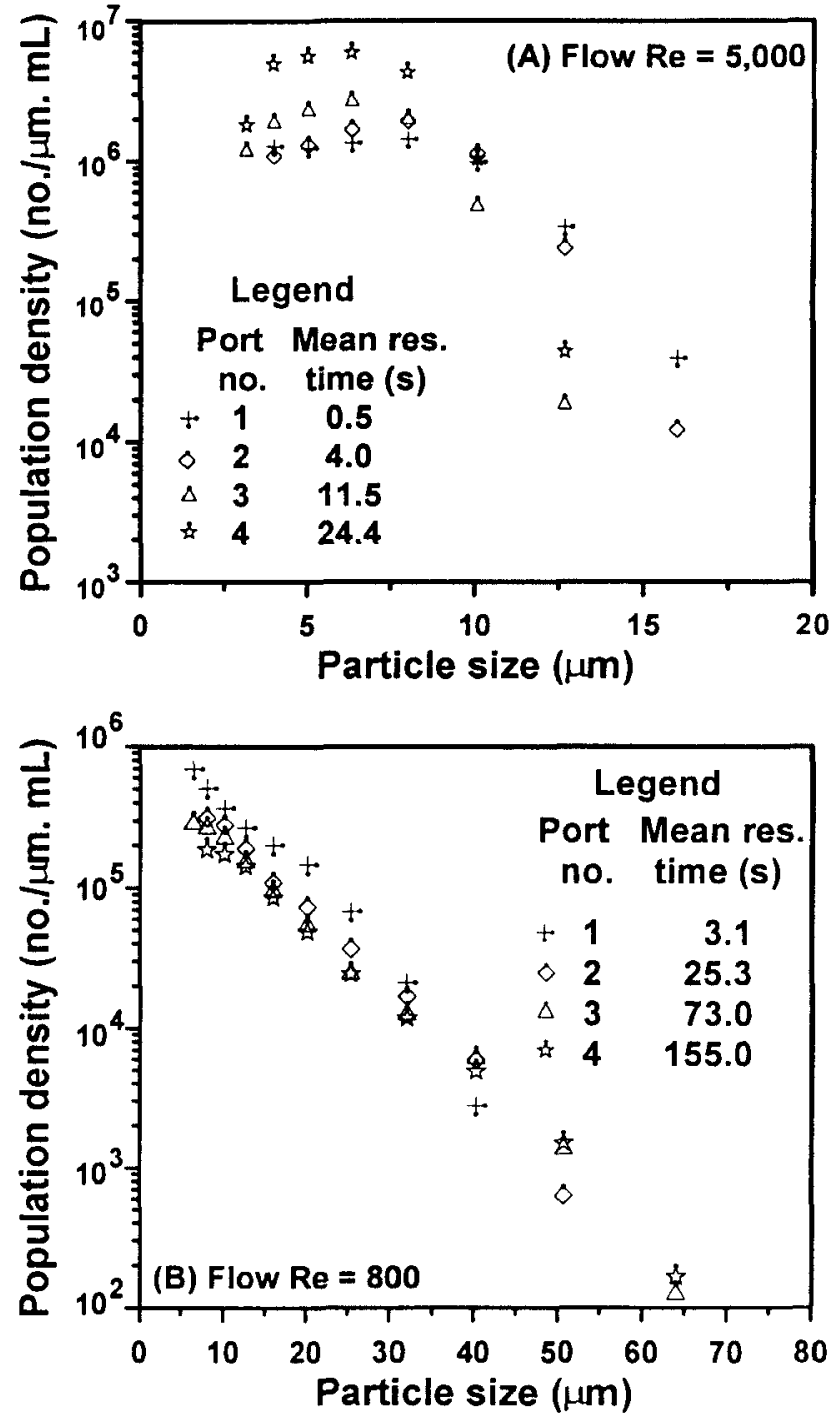

Figure 4 - Effect of the flow regime on the population density of protein particles: Run no. 1, $R e=800$; Run no. $2, \operatorname{Re}=5000$, feed ratio $=1.0 \mathrm{v} / \mathrm{v}$ (aqueous $\mathrm{HCl}$; protein solution) and protein feed concentration $=11.8 \mathrm{~kg} / \mathrm{m}^{3}$.

turbidimeter, Raphael and Rohani (1996b). Details of the experimental method and measurements of the dispersion along the tubular precipitator can be found in Raphael et al. (1995).

\section{Experimental results}

Nucleation takes place in the mixing zone (entrance zone with the static mixers) where the supersaturation is high. Beyond the entrance zone, the supersaturation decreases sharply. The nuclei continue to grow by diffusion to form the primary protein particles. The primary particles aggregate to form larger particles. The maximum stable size of the aggregates is governed by the shear forces exerted by the surrounding fluid. Since the protein supersaturation drops sharply in the tubular precipitator, molecular growth by protein deposition does not contribute significantly to the overall growth (Glatz et al., 1986; Virkar et al., 1982).

The tubular precipitator operating in the laminar flow regime resulted in larger mean particle sizes, which increased with increases in mean residence time (Figure 2). This is due to the continuous growth of smaller particles, 
mainly by an aggregation process. Low fluid-induced shear rate in the laminar flow regime favors the formation of the large aggregates. In the turbulent flow regime, the mean particle sizes were small and varied little with mean residence time. The effect of protein feed concentration on the mean particle sizes (for $R e=800$ and 5000) is presented in Figure 3. Increasing the protein feed concentration under turbulent flow regime (Figure 3A), increased the solids concentration. This resulted in increased particle-particle collisions leading to slightly smaller mean particle sizes due to breakage. In the laminar flow regime (Figure 3B) particle-particle collisions were not high enough to cause significant breakage, and an overall increase in the particle mean size was observed. Figure 4 shows the measured population densities of the precipitate at four sampling ports along the tubular precipitator. For the turbulent flow regime, the population density distribution showed a uni-modal distribution with a narrow spread (Figure 4A). The spread of the PSD decreased with an increase in the mean residence time. This suggests that, the rate of aggregate breakage was higher than the rate of aggregate formation. Close to the precipitator entrance, the dispersion number approaches that of a mixed vessel. As the flow becomes fully developed (ca. 10d), the precipitator approaches the plug flow behavior. In the laminar flow regime, the PSD showed a wide spread (Figure 4B), resulting in a high coefficient of variation $(\mathrm{CV})$ defined in Equation (25). This is attributed to the presence of backmixing, low particle-particle collision energy, and low fluid-induced shear which are favorable conditions for aggregation. In summary, fluid-induced shear and the flow dispersion determine the steady-state PSD.

The amount of recovered solid protein in both laminar and turbulent regimes increased with an increase in the mean residence time (Figure 5). This shows that the solid protein would come out of the solution by molecular diffusion along the length of the precipitator even at low supersaturation levels. Also, increasing the feed concentration resulted in an increase in solids concentration due to a high degree of supersaturation.

\section{Modeling of a tubular precipitator with particle aggregation and breakage}

At steady state, the population balance equation for a tubular precipitator in the presence of aggregation, breakage, and secondary nucleation (Randolph and Larson, 1988) is given by:

$$
\begin{aligned}
& D_{z} \frac{\partial^{2} p}{\partial z^{2}}-u_{z} \frac{\partial p}{\partial z}-\frac{\partial[G p]}{\partial L}+\left(B_{a}-D_{a}\right)+\left(B_{b}-D_{b}\right) \\
& +\beta_{o}^{o} \delta\left(L-L_{o}\right)=0 \ldots \ldots \ldots \ldots \ldots \ldots \ldots \ldots \ldots \ldots \ldots
\end{aligned}
$$

where $p$ (the population density) is a function of particle size $L$ and position $(z)$ along the tubular precipitator. $D_{z}$ is the axial dispersion coefficient, $u_{z}$ is mean flow velocity, $G$ is the molecular particle growth rate, $\left(B_{a}-D_{a}\right)$ is the net rate of particle aggregation, $\left(B_{b}-D_{b}\right)$ is the net rate of particle breakage, and $B_{o}{ }^{\circ}$ is the secondary nucleation rate of particles of size $L_{0}$. Equation (4) assumes no radial dispersion and has initial condition; $p(0, z)=J / G$ as $\mathrm{L} \rightarrow 0$ ( $J$ is the primary nucleation rate which is assumed to be the dominant nucleation mechanism). The boundary condition at the entrance is given by: $u_{z} p(L, 0)-D_{z} d p(L, 0) / d z=0$ that is, no seeding or

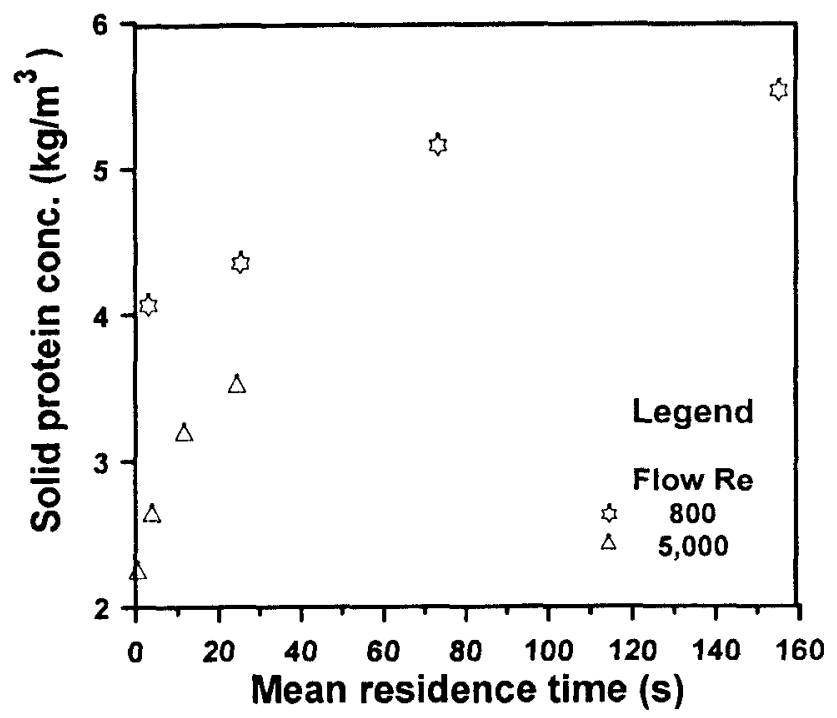

Figure 5 - Effect of flow regime on and solids protein concentration: feed ratio $=1.0 \mathrm{v} / \mathrm{v}$ (aqueous $\mathrm{HCl}$; protein solution) and protein feed concentration $=11.8 \mathrm{~kg} / \mathrm{m}^{3}$.

solids at the entrance. At the exit of the precipitator, the boundary condition is $d p / d z=0$. In this study the radial dispersion was neglected because the ratio of the tube diameter to the length was very small $\left(3 \times 10^{-4}\right)$.

\section{DIMENSIONLESS PARAMETERS}

Introducing the dimensionless parameters defined as:

$$
\zeta=z / z_{T}, x=L / L_{c} \text {, and } y(x, \zeta)=p(x, \zeta) / N_{o}=L_{c} p(L, \zeta) / N_{o}
$$

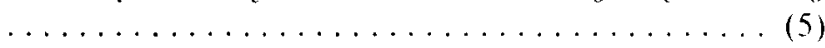

where $P e(\zeta)$ is the dimensionless distance along the tubular precipitator, $z$ is the total length of the tubular precipitator. $x$ is dimensionless particle size, and $L_{c}$ is the maximum measurable particle size divided by the largest root of the Laguerre polynomial. $L_{c}(=3.528 \mu \mathrm{m})$ is used to scale down the experimental particle size range to be within the range of the zeros of the Laguerre polynomial, $y(x, \zeta)$ is the dimensionless population density. $N_{o}$ is a constant value (number density) used to reduce the magnitude of population density. In this study $N_{o}$ was set at $10^{5}$. Substituting dimensionless parameters into Equation (4), and assuming negligible secondary nucleation and that particle growth rate is independent of particle size, Equation (4) becomes:

$$
\begin{aligned}
& \frac{\partial^{2} y}{\partial \zeta^{2}}-P e(\zeta) \frac{\partial y}{\partial \zeta}-P e(\zeta) t_{m} \frac{G \partial y}{L_{c} \partial x}+P e(\zeta) t_{m} \frac{L_{c}}{N_{o}} \\
& {\left[\left(B_{a}-D_{a}\right)+\left(B_{b}-D_{b}\right)\right]=0 \ldots \ldots \ldots \ldots \ldots \ldots}
\end{aligned}
$$

where $P e(\zeta)$ is the Peclet Number $\left(u_{z} z_{T} / D_{z}\right)$. As $P e(\zeta) \rightarrow 0$ the flow approaches the mixed flow regime and as $P e(\zeta) \rightarrow \infty$ the flow approaches the plug flow regime. In dimensionless variables the initial and boundary conditions are:

$$
\begin{gathered}
y(x, \zeta)_{x \rightarrow 0}=\frac{J / N_{0}}{G / L_{0}} ; \quad x \rightarrow 0,0 \leq \zeta \leq 1 \ldots \ldots \\
y(x, 0)-\frac{1}{P e(\zeta)} \frac{d y(x, 0)}{d \zeta}=0 ; \quad \zeta=0, x>0 \ldots \ldots
\end{gathered}
$$




$$
\frac{d y(x, 1)}{d \zeta}=0 ; \quad \zeta=1, x>0
$$

\section{PRIMARY NUCLEATION RATE $(J)$}

The formation of new particles is assumed to be a continuous process which occurs throughout the precipitator. However, the rate of nucleation decreases as the fluid moves downstream. The nucleation rate along the tubular precipitator is expressed as a function of the initial nucleation rate $(J)$, that is, the nucleation rate at $\zeta=0$. At the entrance, there is a high degree of supersaturation leading to high nucleation rate. As the degree of supersaturation decreases along the tubular precipitator, so does the nucleation rate. The nucleation rate is expressed as:

$$
J=J^{0}\left(1-k_{B} \zeta\right)^{a} \ldots \ldots \ldots \ldots \ldots \ldots
$$

The parameter $k_{B}$ determines the rate of depletion in the supersaturation along the precipitator. The initial nucleation rate is determined using the homogeneous nucleation theory for fast reactions (Mullin, 1972) as:

$$
J^{0}=k_{B o} \exp \left[-\frac{k_{m}}{\left(\ln S_{o}\right)^{2}}\right] \ldots \ldots \ldots \ldots \ldots \ldots
$$

where the supersaturation ratio is $S_{0}=C_{0} / C^{*}$, and $k_{m}$ and $k_{B o}$ are constants. $C_{0}$ and $C^{*}$ (calculated from Equations $3 \mathrm{a}$ and 3 c) are the protein feed concentration and the equilibrium protein concentration, respectively. Equation $(8 \mathrm{~b})$ predicts a rapid increase in the nucleation rate with increases in the degree of supersaturation $\left(S_{o}\right)$. Then Equation ( $\left.8 \mathrm{a}\right)$ becomes:

$$
J(\zeta)=k_{B o} \exp \left[-\frac{k_{m}}{\left(\ln S_{o}\right)^{2}}\right]\left(1-k_{B} \zeta\right)^{a}
$$

\section{GROWTH RATE $(G)$}

Molecular growth rate of particles due to deposition of protein from the solution on the particle surface is modeled using a similar argument as for the nucleation rate. The growth rate by molecular mechanism increases with an increase in the concentration gradient. Near the entrance, the growth rate is high and decreases as the concentration gradient decreases along the tubular precipitator. Therefore, the growth rate is expressed as a function of the initial growth rate $\left(G_{0}{ }^{\circ}\right)$ :

$$
G(\zeta)=G_{o}^{o}\left(1-k_{G} \zeta\right)^{h}
$$

where $G_{o}{ }^{o}$ is defined as:

$$
G_{o}^{0}=k_{G o} \sigma_{o}^{g}
$$

The relative supersaturation at $\zeta=0$ is given by: $\sigma_{o}=(C o$ $\left.-C^{*}\right) / C^{*}$. The parameter $g$ determines the mechanism governing particle growth. When $g=1$, the particle growth is diffusion controlled, $1<g<2$ implies that screw dislocation mechanism controls the particle growth, and when $g>2$ polynuclear mechanism controls the particle growth. Substituting Equation (9b) into Equation (9a) yields:

$$
G(\zeta)=k_{G o} \sigma_{o}^{g}\left(1-k_{G} \zeta\right)^{h}
$$

\section{PARTICLE BREAKAGE RATE}

The particle breakage rate term, $B=\left(B_{b}-D_{b}\right)$, is assumed to be a two equal body volume-conserved breakage (Glatz et al., 1986). That is, a breaking particle (death) results in the birth of two particles of equal volume. This simple model is given as:

$$
\begin{aligned}
& D_{b}(L)=k_{d} L^{d} p(L, z) \ldots \ldots \ldots \ldots \ldots \ldots \ldots \ldots \ldots \ldots \ldots \ldots \ldots \ldots \ldots \ldots \ldots \\
& B_{b}=2 D_{b}\left(2^{1 / 3} L, z\right) \ldots \ldots \ldots \ldots \ldots \ldots \ldots
\end{aligned}
$$

Then the net rate of particle breakage, $B$ is given as:

$$
B=k_{d} L^{d}\left[2^{d / 3+1} p(1.26 L, z)-p(L, z)\right] \ldots \ldots \ldots \ldots
$$

Introducing the dimensionless variables into Equation (12), results in:

$$
B=k_{d} \frac{N_{o}}{L_{c}}\left(x L_{c}\right)^{d}\left[2^{d / 3+1} y(1.26 x, \zeta)-y(x, \zeta)\right] \ldots
$$

\section{PARTICLE AGGREGATION RATE}

The particle aggregation rate is modeled using the formulation of Hulburt and Katz (1964). The death and birth of particles due to aggregation is given by:

$$
\begin{gathered}
A(L)=\left(B_{a}-D_{a}\right)=\frac{L^{2}}{2} \int_{0}^{L} \beta\left(L_{1}, L_{2}\right) \frac{p\left(L_{1}, z\right) p\left(L_{2}, z\right)}{L_{2}^{2}} d L_{1} \\
-p(L, z) \int_{0}^{\infty} \beta\left(L_{1}, L_{2}\right) p\left(L_{1}, z\right) d L_{1} \ldots \ldots \ldots \ldots \ldots
\end{gathered}
$$

where $L_{2}{ }^{3}=L^{3}-L_{1}{ }^{3}$. Because of the limited knowledge of aggregation kernel, $\beta\left(L_{1}, L_{2}\right)$, it is assumed to be constant, $\beta_{o}$, and independent of the particle size. Introducing the dimensionless variables into Equation (14) yields:

$$
\begin{aligned}
& A(\zeta)=P_{A} \frac{x^{2}}{2} \int_{0}^{x} \frac{y\left[\left(x^{3}-\varepsilon^{3}\right)^{1 / 3}, \zeta\right] y(\varepsilon, \zeta)}{\left(x^{3}-\varepsilon^{3}\right)^{2 / 3}} d \varepsilon \\
& -P_{A} y(x, \zeta) \int_{0}^{\infty} y(\varepsilon, \zeta) d \varepsilon \ldots \ldots \ldots \ldots
\end{aligned}
$$

where $P_{A}=\beta_{o} N_{o}{ }^{2} / L_{c}$ and $\varepsilon=L_{1} / L_{c}$ is the size of particles less than size $x$.

\section{THE SOLUTION OF THE POPULATION BALANCE EQUATION}

The resulting population balance equation (PBE) after introducing the aggregation and breakage terms is a non-linear integro-differential equation with initial and boundary conditions. In this study, the solution of the PBE is obtained using orthogonal collocation-multiple shooting method. The non-linear multiple shooting method (MSM), Ascher et al. (1988), is used to solve the PBE in the $\zeta$ direction (precipitator length), whereas the orthogonal collocation method (OCM) is used to solve the problem in the $x$ direction, (particle size).

The collocation method allows the use of uneven mesh in the $x$ direction while the MSM is applied on the even grid 
mesh. The procedure is to assume a Lagrange polynomial as a solution of the PBE. This trial solution is selected from a set of functions defined in the domain $[0, \infty)$. For this reason, the Laguerre functions were selected. The trial solution is defined as:

$$
y_{n}(x, \zeta)=\sum_{i=1}^{n} \alpha_{i}(\zeta) \Phi_{i-1}(x) \ldots \ldots \ldots \ldots \ldots \ldots
$$

where $\alpha(\zeta)$ is a function of $\zeta$ and $\Phi(x)$ is a function of $x$ In Equation $16, y_{n}$ is a $(n-1)$ th polynomial in $x$.

The function $\Phi(x)$ is defined as:

$$
\Phi_{i}(x)=e^{-x} \psi_{i}(x)
$$

$\psi_{i}(x)$ are the Laguerre polynomials. The $n$th Laguerre polynomial (Courant and Hilbert, 1966) is defined as:

$$
\psi_{n}(x)=\sum_{j=0}^{n} \frac{(-1)^{j}(n !)^{2} x^{j}}{j !(n-j) !}
$$

with $\psi_{o}(x)=1, \psi_{1}(x)=-x+1$, and $\psi_{2}(x)=x^{2}-4 x+2$. These polynomials are orthogonal with respect to the exponential weighting in the range $[0, \infty)$. The solution procedure is to substitute Equation (16) in the PBE. Since the expansion solution is an approximation, a non-zero residual, $R(x, \zeta)$ will result after this substitution. The basis of the orthogonal collocation method is to set this residual to zero at all collocation points, $x_{i}$. This is done by determining the coefficients $\alpha_{i}(\zeta)(i=0,1,2, \ldots n-1)$ so that, $R_{i}\left(x_{i}, \zeta\right)=0$. For an "exact" solution when using the orthogonal collocation method, it is required that the collocation points $x_{i}$ be the roots (zeros) of the $n$th order Laguerre polynomial (Villadsen and Michelsen, 1978). Substituting the approximate solution into the PBE and introducing the matrix notation (see Appendix) results in:

$$
\begin{gathered}
\frac{d_{\alpha}^{-2}}{d \zeta^{2}}-\operatorname{Pe}(\zeta) \frac{d \bar{\alpha}}{d \zeta}-\operatorname{Pe}(\zeta) \frac{G t_{m}}{L_{c}}(\overline{\bar{\Phi}}-1 \overline{\bar{T}}) \bar{\alpha}+ \\
\operatorname{Pe}(\zeta) \frac{L_{c} t_{m}}{N_{o}}[\bar{A}+\bar{B}]=\overline{\bar{\Phi}}^{-1} \bar{R}(x, \zeta) \ldots
\end{gathered}
$$

where $\bar{R}(x, \zeta)$ is the residue matrix. Therefore, the PBE has been transformed into a set of second order ordinary differential equations (boundary value problem). The corresponding boundary conditions in matrix form are:

$$
\begin{aligned}
& \overline{\bar{\Phi}} \bar{\alpha}(\zeta)_{x \rightarrow 0}=\frac{J / N_{0}}{G / L_{0}} ; \quad x \rightarrow 0,0 \leq \zeta \leq 1 \ldots \ldots \ldots \\
& \operatorname{Pe}(\zeta) \bar{\alpha}(\zeta)-\frac{d \bar{\alpha}}{d \zeta}=0 ; \quad \zeta=0, x>0 \ldots \ldots \ldots \\
& \overline{\bar{\Phi}} \frac{d \bar{\alpha}}{d \zeta}=0 ; \quad \zeta=1, x>0 \ldots \ldots \ldots
\end{aligned}
$$

\section{Simulation OF THE MODEL AND SENSITIVITY ANALYSIS}

In order to determine the structural accuracy of the overall model and its behavior to changes in the kinetic parameters,
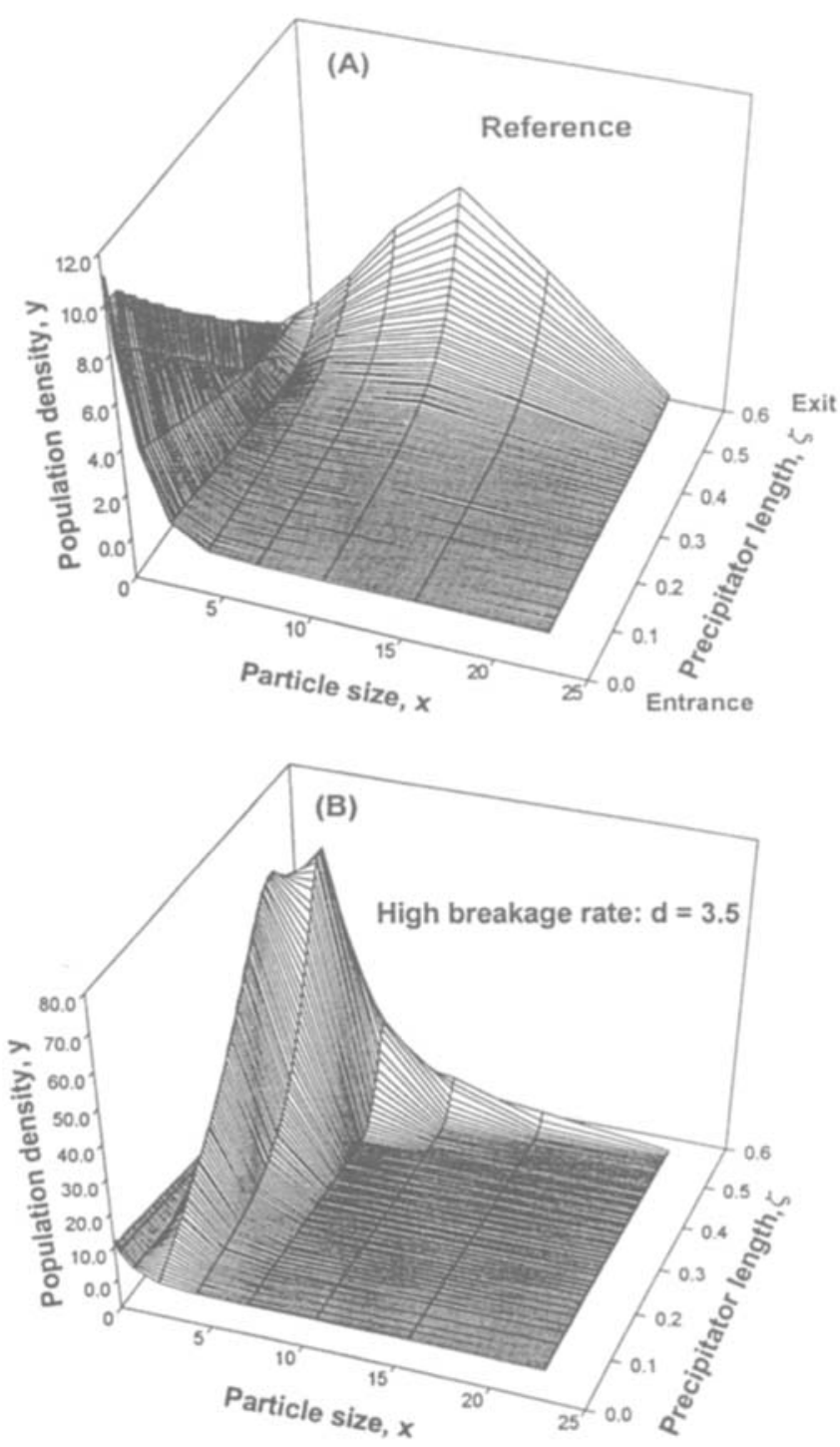

Figure 6 - Reference PSD and simulated PSD profiles obtained by varying the breakage rate parameter $d$.

it was necessary to carry out a detailed sensitivity analysis. Due to the lack of experimental data in the literature, the PBE was solved using a hypothetical PSD derived from skewed normal distribution curves. This sensitivity analysis would also demonstrate the flexibility and the convergence of the proposed numerical scheme using different model parameters on the PSD profiles. The optimum model parameters which satisfy the boundary conditions (BC) were determined by the optimization method. The dimensionless PSDs at the port near the entrance, $\zeta_{0}=0.02$, and at some other point, $\zeta_{e}=0.5$, along the precipitator length, were assumed to be continuous and represented by simple distribution equations. At the entrance the PSD was defined as:

$$
y\left(x, \zeta_{o}\right)=\frac{K_{o}}{\mu_{o}} \exp \left[-\frac{\left(x-x_{o}\right)}{\mu_{o}}\right]
$$

where $x_{0}$ is assumed to be the dimensionless nuclei size (very small number $=0.001$ ), $\mu_{o}=1, K_{0}=10$ and $\zeta_{e}=0.5$. The density function distribution was assumed as:

$$
y\left(x, \zeta_{e}\right)=\frac{K_{e}}{\mu_{e}} \exp \left[-\frac{\left(x-x_{e}\right)^{2}}{\mu_{e}^{2}}\right] \ldots \ldots \ldots \ldots
$$


TABLE 3

Values of Parameters Used in the Model Simulation

(Reference Data)

\begin{tabular}{llll}
\hline Nucleation rate: & $a=3.5$ & $k_{B}=0.5$ & $k_{B o}=1 \times 10^{8} \mathrm{no} / \mathrm{mL} \cdot \mathrm{s}$ \\
Growth rate: & $b=2.0$ & $k_{G}=0.30$ & $k_{G o}=4 \times 10^{-5} \mu \mathrm{m} / \mathrm{s}$ \\
Breakage rate: & $d=0.2$ & $k_{d}=5 \times 10^{-6}$ & \\
Aggregation rate: & $\beta_{o}=1.0 \times 10^{15} \mu^{4} \cdot \mathrm{mL} \cdot \mathrm{s} / \mathrm{no}$ & & \\
Protein conc.: & $C_{o}=12.0 \mathrm{~kg} / \mathrm{m}^{3}$ & $C^{*}=2.0 \mathrm{~kg} / \mathrm{m}^{3}$ & \\
Flow velocity: & $u_{z}=0.13 \mathrm{~m} / \mathrm{s}$ & & \\
\hline
\end{tabular}
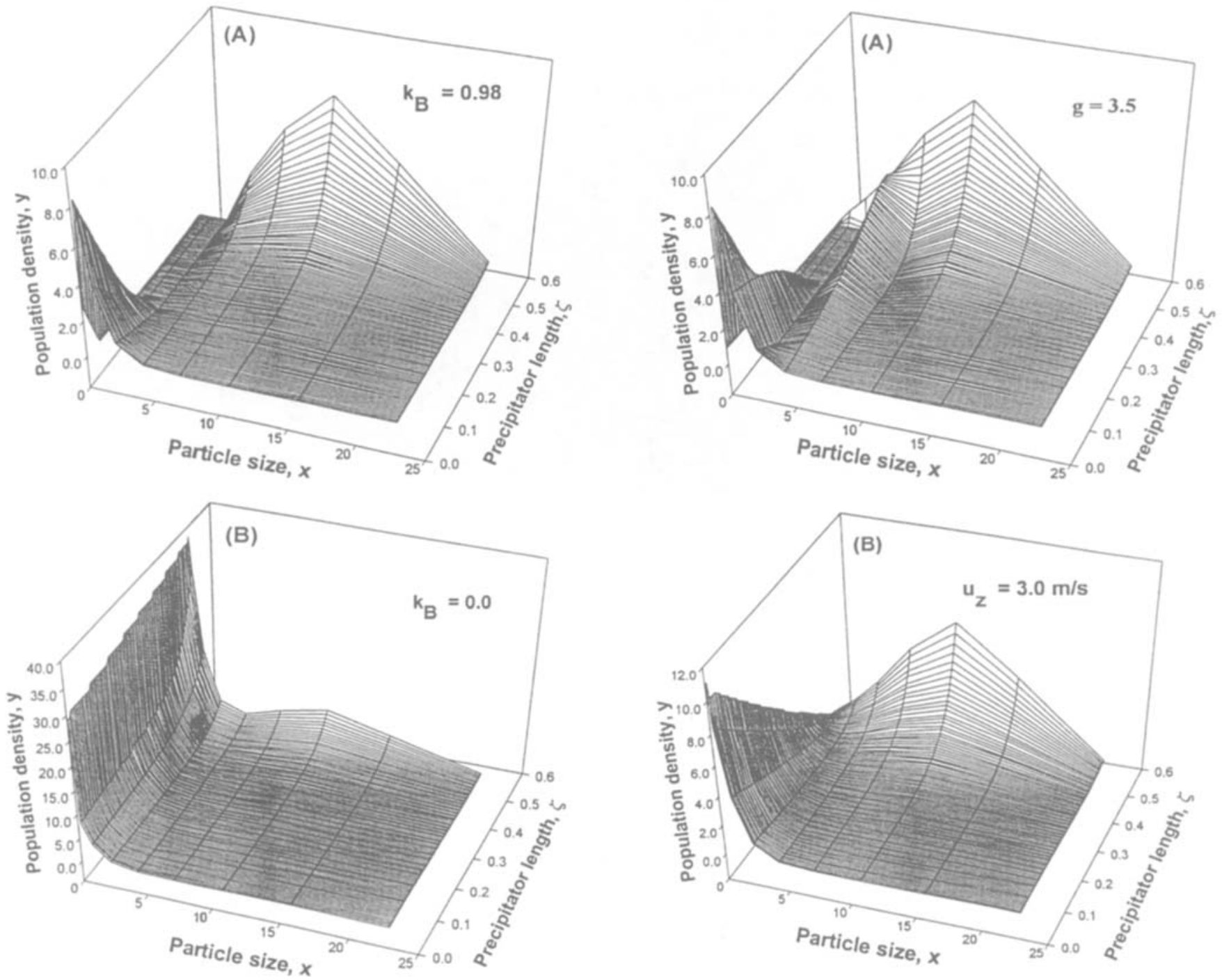

Figure 7 - Simulated PSD profiles obtained by varying the nucleation rate parameter $k_{B}$.

where $x_{c}$ was assumed to be the dimensionless exit mean particle size $(=11), \mu_{e}=1.41 x_{e} C V_{e}, K_{e}=10 \pi^{-1 / 2}$, and $C V_{e}=$ 0.45 . The two PSD are shown in Figure 6A. The entrance (port 1) PSD shows the existence of many small particles due to homogeneous nucleation. Then, it is assumed that after sometime, the slurry will have moved a distance $\zeta_{e}(=0.5)$ along the tubular precipitator. During this time, nucleation, particle growth, particle aggregation, and particle breakage take place. Using the two PSDs as boundary conditions, along with the assumed values of parameters given in Table 3 (not optimized), the PBE was solved using OCMSM to generate the intermediate PSD profiles (no intermediate constraints). When the breakage rate is increased, by increasing the constant $k_{d}$ or the parameter $d$, the PSD shifts towards

Figure 8 - Simulated PSD profiles: A) obtained by varying the growth rate parameter $g$; B) obtained by varying the flow velocity $u_{.}$.

the small particle size range (see Figure 6B), indicating that the population density of fine particles has increased. Decreasing the number of initial nuclei by increasing parameter $a$ or $k_{B}$, leads to a fast depletion of the supersaturation. This results in a low population of the small particles along the tubular precipitator, due to the absence of the nucleation process (Figure 7A). Whereas, if the value of $k_{B}$ is made zero (slow depletion of supersaturation), the nucleation process becomes very slow and takes place throughout the tubular length. This, together with particle breakage results in high values of fine particles (Figure 7B).

Figure 8A shows the PSD profiles generated by varying the growth rate exponent. Growth rate is associated with the molecular growth of the small particles and primary particles 
TABLE 4

Summary of the Runs in the Tubular Precipitator used in the Determination of Kinetic Parameters, Experimental Conditions and Measured Mean Particle Size and CV of Samples from Ports 2 and 3

\begin{tabular}{lcccrrrr}
\hline $\begin{array}{l}\text { Run } \\
\text { No. }\end{array}$ & $\begin{array}{c}C o \\
\left(\mathrm{~kg} / \mathrm{m}^{3}\right)\end{array}$ & $\begin{array}{c}C^{*} \\
\left(\mathrm{~kg} / \mathrm{m}^{3}\right)\end{array}$ & $\begin{array}{c}u_{z} \\
(\mathrm{~m} / \mathrm{s})\end{array}$ & \multicolumn{1}{c}{$\begin{array}{c}d_{i 2} \\
(\mu \mathrm{m})\end{array}$} & \multicolumn{1}{c}{$\begin{array}{c}d_{i 3}{ }^{\S} \\
(\mu \mathrm{m})\end{array}$} & $\begin{array}{c}C V_{i 2} \\
(\%)\end{array}$ & $\begin{array}{c}C V_{i 3} \\
(\% / 1)\end{array}$ \\
\hline L1 & 11.8 & 1.9 & $0.13(800)+$ & $27.8 \pm 1.1$ & $30.7 \pm 1.7$ & 38.5 \\
L2 & 11.8 & 1.9 & $0.83(5000)+$ & $8.6 \pm 1.1$ & $7.9 \pm 1.7$ & 43.1 \\
L6 & 2.8 & 0.47 & $0.13(800)+$ & $22.8 \pm 1.1$ & $27.6 \pm 1.7$ & 3.3 & 23.1 \\
L7 & 2.8 & 0.47 & $0.83(5000)+$ & $10.2 \pm 1.1$ & $9.5 \pm 1.7$ & 22.1 & 28.6 \\
\hline
\end{tabular}

+ Total flow Re number in the tubular precipitator.

$\S$ Recalculated mean particle size using particle size ranges corresponding to the first 8 zeros of the Laguerre polynomial.

TABLE 5

Initial Estimates of Kinetic Parameters, the Search Range Used in Optimization, and the Final Optimum Values

\begin{tabular}{|c|c|c|c|c|c|}
\hline Equation & Parameter & Min. value & Max. value & Initial value & Optimum value \\
\hline Nucleation rate: & $\begin{array}{l}a \\
k_{B} \\
k_{B o}(\mathrm{no} / \mathrm{mL} \cdot \mathrm{s}) \\
k_{m}\end{array}$ & $\begin{array}{l}0.5 \\
0.001 \\
1.0 \\
1.0\end{array}$ & $\begin{array}{c}10.0 \\
0.98 \\
10^{14} \\
10^{2}\end{array}$ & $\begin{array}{c}1.0 \\
0.5 \\
10^{6} \\
50.0\end{array}$ & $\begin{array}{l}=2.567 \\
=0.353 \\
=2.385 \times 10^{10} \\
=61.420\end{array}$ \\
\hline Growth rate: & $\begin{array}{l}b \\
k_{G} \\
k_{G o}(\mu \mathrm{m} / \mathrm{s}) \\
g\end{array}$ & $\begin{array}{l}0.0 \\
0.001 \\
0.0 \\
0.0\end{array}$ & $\begin{array}{l}5.0 \\
0.98 \\
1.0 \\
5.0\end{array}$ & $\begin{array}{l}1.0 \\
0.5 \\
0.1 \\
1.0\end{array}$ & $\begin{array}{l}=1.842 \\
=0.199 \\
=5.107 \times 10^{4} \\
=1.512\end{array}$ \\
\hline Breakage rate: & $\begin{array}{l}d \\
k d\end{array}$ & $\begin{array}{l}0.1 \\
0.0\end{array}$ & $\begin{array}{l}5.0 \\
5.0\end{array}$ & $\begin{array}{l}1.0 \\
0.1\end{array}$ & $\begin{array}{l}=0.784 \\
=2.744 \times 10^{6}\end{array}$ \\
\hline Aggregation rate: & $\beta_{o}\left(\mu \mathrm{m}^{4} \cdot \mathrm{mL} \cdot \mathrm{s} / \mathrm{no}\right) 0.0$ & & $10^{-9}$ & $10^{-12}$ & $=9.549 \times 10^{10}$ \\
\hline
\end{tabular}

Final value of $H=0.577$

before they join with larger aggregates. Increasing the growth rate exponent $(g)$ results in multi-modal PSD. This shows the presence of mixed sizes of particles, the aggregates and large particles formed by molecular growth. Larger values of the growth exponent $(g)$ leads to multiple solutions of the PBE solution.

Increasing the flow velocity (high Reynolds number) shows that the PSD does not form a multi-modal distribution (Figure 8B). This might be due to high shear rate caused by turbulent flow resulting in breakage of the intermediate sized aggregates or that, the particle-particle collisions are not effective in forming a lasting aggregate.

These parameter sensitivity studies, as illustrated in these examples, shows that the numerical scheme is flexible enough to generate the PSD profiles to match the experimentally obtained PSD (boundary conditions). A similar scheme was used during parameter optimization where four different data sets (each with 2 inner constraints) were used to determine the best set of parameters resulting in the minimum residue.

\section{DETFRMINATION OF PRECIPITATION KINETIC PARAMETERS} FROM EXPERIMENTAL DATA

A total of 11 parameters from model equations (nucleation rate equation parameters: $a, k_{B}, k_{B o}$, and $k_{m}$; growth rate equation parameters: $b, k_{G}, k_{G o}$, and $g$; breakage rate equation parameters; $d$, and $k_{d}$; and aggregation rate equation parameter: $\beta_{o}$ ) were determined by the optimization method. The estimated parameters were then substituted into the respective equation for solving the population density equation along the tubular precipitator. The calculated population density data were used to determine the local mean particle size and the coefficient of variation (corre- sponding to experimental sampling ports). Parameter optimization was done using the Simulated Annealing Method (SAM), Goffe et al. (1994), for determination of the global parameters. The method is slow, but sure. The Multiple Shooting Method (MSM) was used to obtain the PSD profiles between the two boundary conditions, the entrance port and the exit port, using the iterative method. During each calculation pass, the boundary conditions were satisfied. The PSD for the interior ports (2 and 3 ) were represented using the mean particle size and the coefficient of variation. These interior data were used as constraints for the optimization equation, that is, the optimum parameters should satisfy the two boundary conditions profiles and the interior distributions at ports 2 and 3. Four sets of experimental data were used for this optimization (Table 4). The objective function to be optimized was given as:

$$
\min _{P} H=\sum_{\substack{i=1 \\ j=2}}^{\substack{i=4 \\ j=2}}\left[\left(\frac{d m_{i, j}}{d_{i, j}}-1\right)^{2}+\left(\frac{C V m_{i, j}}{C V_{i, j}}-1\right)^{2}\right] \ldots
$$

where $P$ is a matrix of parameters, $\left[a k_{B} k_{B o} k_{m} b k_{i} k_{(i o} g d\right.$ $\left.k_{d} \beta_{o}\right], d m_{i, j}$ and $C V m_{i, j}$ are the calculated values of the mean particle size and the coefficient of variation for run $i$ at port $j$, respectively. $d_{i j}$ and $C V_{i j}$ are the corresponding experimental values. $d_{m i j}$ and $C V_{m i j}$ were calculated as:

$$
d_{m_{i j}}=\frac{\sum_{j=1}^{n} L_{j}^{4} p_{j} \Delta L_{j}}{\sum_{j=1}^{n} L_{j}^{3} p_{j} \Delta L_{j}}
$$



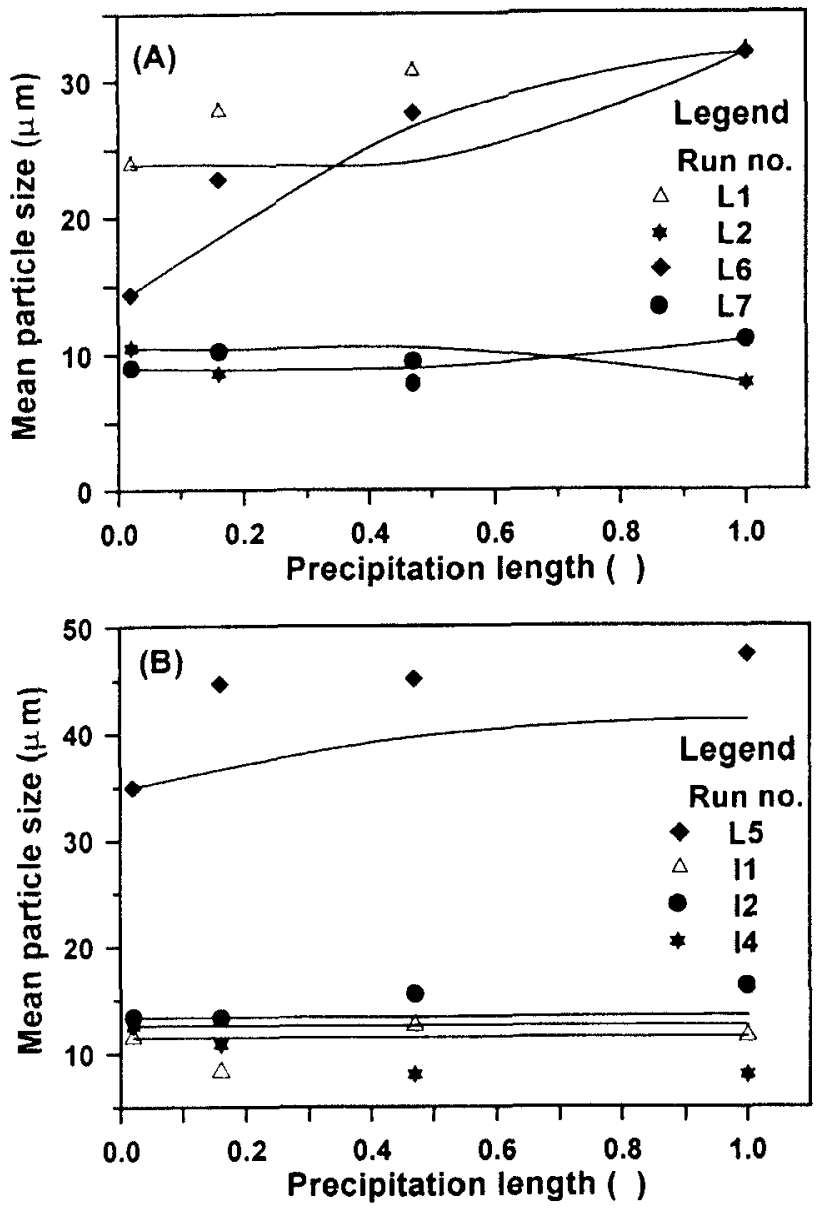

Figure 9-- A) Model fit to the experimental data using the optimum parameters; B) Model prediction of the experimental data.

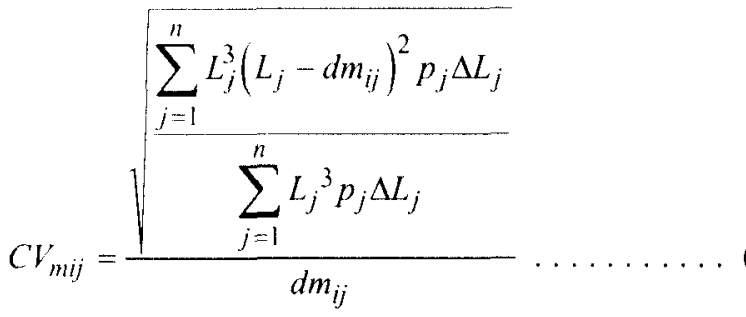

Table 5 shows the list of the initial estimates and the search range used for optimization. Some of these data were based on the knowledge from previous studies (Raphael et al., 1995 and Raphael and Rohani, 1996a).

The numerical algorithm starts by entering the scaled down PSD for the boundary conditions at selected node points (the roots of the trial function). This was achieved by fitting the experimental PSD data using a cubic spline polynomial, then interpolated at the desired nodes. The interpolated data were checked for accuracy by recalculating the mean particle size and the $C V$, then compared with the original data. In all interpolated data used in this parameter estimation, the accuracy was within $\pm 8 \%$ for the mean particle sizes smaller than $10 \mu \mathrm{m}$, and within $\pm 5 \%$ for the mean particle sizes larger than $10 \mu \mathrm{m}$. Interpolated $C V$ data showed discrepancies of up to $\pm 50 \%$ because the roots of the Laguerre polynomial did not match the experimental measuring sizes (many roots were in the lower end and sparsely distributed in the higher end). Then, the initial guess of parameters for the optimization routine were entered. The opti-

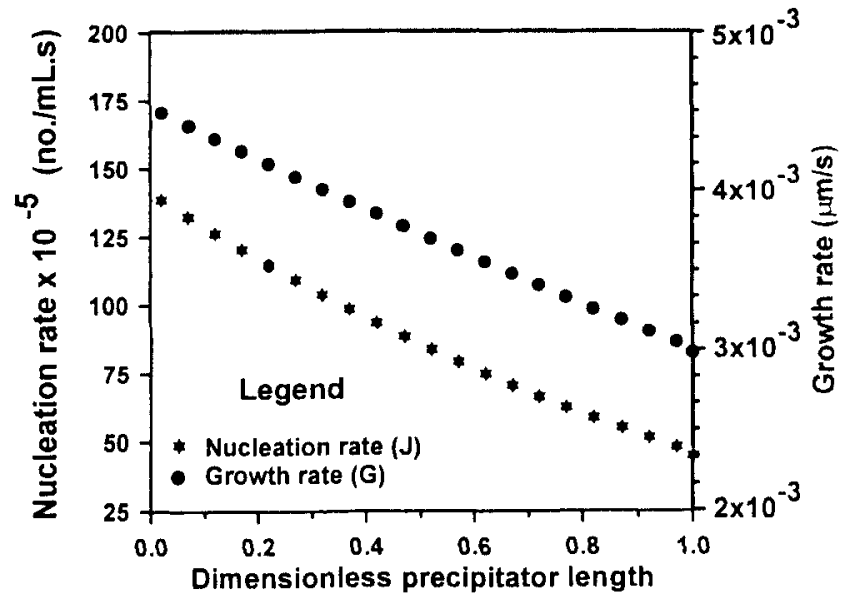

Figure 10 - Calculated nucleation and growth rates along the tubular precipitator using optimized parameters.

mization program (Simulated Annealing Method) solved the objective function value by calling the BVP-ODE solver with 101-equally spaced node points in $\zeta$ direction (along the tubular precipitator). The BVP-ODE solver (Non-linear Multiple Shooting Method (MSM) by Ascher et al., 1988) called the other subroutines which calculated the net aggregation and net breakage terms. The integrals in the aggregation term were estimated using a Gaussian-Laguerre quadrature with 9 terms. After the integration, the MSM generated the calculated PSD profiles (between the boundary conditions, inclusive) for all four data sets used. The optimization routine extracted the estimated mean particle sizes and the $C V_{s}$ representing the interior ports ( 2 and 3 ) for substitution into the objective function. The method is repeated until the objective function is satisfied and the consecutive values of the calculated parameters satisfy the set tolerance $\left(10^{-4}\right)$.

The set of the optimum parameters obtained from this study are presented in Table 5 and the model fits to the experimental data are presented in Figure 9A. Figure 10 shows the calculated profiles for the nucleation and growth rates along the tubular precipitator. Both rates decrease progressively along the tubular precipitator as the degree of supersaturation decreases. This confirms the observed increases in solids concentration (Figure 5) with residence time, which was due to thte formation of new solids from the solution. Therefore, the assumption that the entire solid protein comes out of the solution in $1 \mathrm{~s}$ is not realistic.

\section{MODEL PREDICTIONS OF THE EXPERIMENTAL RESULTS}

The kinetic parameters obtained from the experimental data were used to predict the PSD from four different experiments (Table 5). Due to the lack of experimental data on the kinetics of the sunflower protein precipitation in the literature, the validation of the model was performed using our own data. This time, instead of solving the PBE as a boundary value problem, it was solved as an IVP (initial value problem) using the LSODE algorithm (Hindmarsh, 1980). In order to start the integration, it was required to supply the initial PSD. It was hoped that, by supplying the feed concentration and the total flow velocity, the program should be able to generate the entire PSD profile for the tubular precipitator (starting from initial nucleation at $\zeta=0$ ). It turned out that, the problem was very stiff and at reduced tolerances, the predicted values showed a large discrepancy from 
the experimental values. To circumvent this stiffness, the experimental data from the first port $(\zeta=0.02$, close to the precipitator entrance) were used as the initial condition. Predicted and experimental results are compared in Figure 9B. For small mean particle sizes, the predicted results showed a wider deviation from the experimental results. When the experimental errors are taken into account the discrepancies are within the experimental errors.

\section{CRITICAL EVALUATION OF THE KINETICS OF PRECIPITATION ANI KINETIC PARAMETERS}

The models presented here for nucleation, growth, breakage, and aggregation rates, although not fundamental, are based on sound assumptions and represent logical dependence on key process variables. For example, the primary nucleation rate is shown in Equation $(8 \mathrm{c})$ to be a strong function of supersaturation. The supersaturation decreases along the length of the tubular precipitator and therefore, nucleation rate is correlated with the dimensionless reactor length. A similar dependence on the supersaturation and the dimensionless reactor length is assumed for the growth rate in Equation (9c). Equation (10) demonstrates a size-dependent death rate due to breakage. The larger the particles, the higher is the probability of their breakage upon collision. Since particle breakage is a volume-conserved process, Equation (11) associates the birth rate of particle of size $L$ to the death rate of particles of size $2^{1 / 3} L$. The aggregation rate is represented by Equation (15), which is based on Smoluchowski's model with a size-independent aggregation kernel. There is no attempt in the literature to model such a complex process involving nucleation, growth, breakage, and aggregation sub-processes in a tubular reactor. The overall model and its solution methodology, presented in the present work, are the first attempt to undertake such a task. The overall model involves too many parameters (11 in total). This, however, is inevitable due to the lack of fundamental theory on the nature of nucleation, growth, breakage, and aggregation sub-processes. Another limiting fact is the lack of previous experimental data in the literature on these sub-processes involving the precipitation of proteins. As more fundamental models for nucleation, growth, aggregation, and breakage sub-processes become available in the future, the limitation of the overall model will be relaxed and the number of estimated kinetic parameters will be reduced. In the present work, we have shown that the model, despite these shortcomings, predicts correct qualitative trends (Figures 6 to 8 ) and particle size distribution (Figure 9B) using the optimized kinetic parameters.

\section{Conclusions}

In this study, kinetics parameters of the sunflower protein precipitation in the tubular precipitator by isoelectric method (aqueous $\mathrm{HCl}$ ) were determined. The non-linear PBE of the tubular precipitator including primary nucleation, molecular growth, growth by aggregation, and breakage of aggregates was solved using the orthogonal-collocation and multiple shooting methods. The estimated kinetics parameters were used to check the validity of the model by predicting the PSD of experiments which were not used in the parameter estimation algorithm (Figure 9B). The predicted PSDs along the tubular precipitator were within the experimental errors. Using these kinetic parameters, the length of the tubular precipitator required to give the desired mean particle size of the precipitate can be calculated.

\section{Appendix: Solution of the PBE}

Equation (16 )was used to approximate both interior and initial population densities. This method is referred to as mixed method. Equation (16) has a total of $n$ adjustable parameters, $\alpha_{i}(\zeta)$. One for the initial condition $\left(x_{1}=0\right)$ and $(n-1)$ for the interior points. Equation 16 can be written in matrix form as:

$$
\bar{Y}=\overline{\bar{\Phi}} \bar{\alpha}
$$

where:

$$
\begin{aligned}
& \bar{\alpha}=\left[\begin{array}{llllll}
\alpha_{0}(\zeta) & \alpha_{1}(\zeta) & \alpha_{2}(\zeta) & \ldots & \alpha_{n-1}(\zeta)
\end{array}\right]^{T} \ldots \ldots \\
& \bar{Y}=\left[\begin{array}{lllll}
y\left(x_{1}, \zeta\right) & y\left(x_{2}, \zeta\right) & y\left(x_{3}, \zeta\right) & \ldots & y\left(x_{n}, \zeta\right)
\end{array}\right]^{T} \ldots \ldots
\end{aligned}
$$

and,

$$
\overline{\bar{\Phi}}=\left[\begin{array}{cccc}
\phi_{1,0} & \phi_{1,1} & \ldots & \phi_{1, n-1} \\
\phi_{2,0} & \phi_{2,1} & \ldots & \phi_{2, n-1} \\
\vdots & \vdots & \vdots & \vdots \\
\phi_{n, 0} & \phi_{n, 1} & \ldots & \phi_{n, n-1}
\end{array}\right] \ldots \ldots \ldots
$$

where $\phi_{i, k}=e^{-x} \psi_{k}(x)$ for $x=x_{i}, i=1,2,3, \ldots n$ and $k=$ $0,1,2,3, \ldots n-1$. Similarly, the derivatives are given by:

$$
\begin{aligned}
& \frac{d \bar{Y}}{d t}=\sum_{i=1}^{n} \alpha_{i}(\zeta) \frac{d\left[e^{-x} \psi_{i-1}(x)\right]}{d x}=\overline{\bar{T}} \bar{\alpha} \\
& \frac{d \bar{Y}}{d \zeta}=\overline{\bar{\Phi}} \overline{\alpha^{\prime}} \ldots \ldots \ldots \ldots \ldots \ldots \ldots \ldots \ldots \ldots \ldots \ldots \ldots \ldots \ldots \ldots
\end{aligned}
$$

where:

$$
\begin{aligned}
& \overline{\alpha^{\prime}}=\left[\begin{array}{llll}
\alpha_{0}^{\prime}(\zeta) & \alpha_{1}^{\prime}(\zeta) & \ldots & \alpha_{n}^{\prime}(\zeta)
\end{array}\right]^{T} \ldots \ldots \ldots \ldots \ldots \\
& \overline{\alpha^{\prime \prime}}=\left[\begin{array}{llll}
\alpha_{0}^{\prime \prime}(\zeta) & \alpha_{1}^{\prime \prime}(\zeta) & \ldots & \alpha_{n}^{\prime}(\zeta)
\end{array}\right]^{T} \ldots \ldots \ldots \ldots \ldots
\end{aligned}
$$

and,

$$
\overline{\bar{T}}=\left[\begin{array}{cccc}
\gamma_{1,0} & \gamma_{1,1} & \ldots & \gamma_{1, n-1} \\
\gamma_{2,0} & \gamma_{2,1} & \ldots & \gamma_{2, n-1} \\
\vdots & \vdots & \vdots & \vdots \\
\gamma_{n, 0} & \gamma_{n, 1} & \ldots & \gamma_{n, n-1}
\end{array}\right]
$$

where $\gamma_{i, k}=e^{-x}\left[k \psi_{k-1}^{\prime}(x)-k \psi_{k-1}(x)-\psi_{k}(x)\right]$ for a given $x=$ $x_{i}(i=1,2,3, \ldots n)$ also $\psi_{o}^{\prime}=0$ and $\psi_{1}^{\prime}=-1 . x_{i}$ are the $n$ roots of the Laguerre polynomial.

\section{PARTICLE AGGREGATION}

The integrals in the aggregation equation, Equation (15), were solved using Gaussian-Laguerre quadrature defined as:

$$
\int_{0}^{\infty} h(x) d x=\sum_{i=1}^{n} w_{i} e^{x_{i}} h\left(x_{i}\right) \ldots \ldots \ldots \ldots \ldots
$$


where $x_{i}$ are the $n$ zeros of the Laguerre polynomial and $w_{i}$ are the corresponding weighting factors. Equation (15) can be written in matrix form as:

$$
\bar{A}=P_{A}\left[\frac{x_{k}}{2} \overline{I_{h}}-I_{x} \bar{Y}\right] .
$$

where:

$$
\begin{aligned}
& A=\left[\begin{array}{llllll}
A\left(x_{1}, \zeta\right) & A\left(x_{2}, \zeta\right) & A\left(x_{3}, \zeta\right) & \ldots & A\left(x_{n}, \zeta\right)
\end{array}\right]^{T} \ldots \\
& I x_{k}=\left[I_{x 1} I_{x 2} \ldots I x_{n}\right]^{T}
\end{aligned}
$$

and,

$$
\begin{aligned}
& I x_{k}=\int_{0}^{x_{k}} f(\varepsilon, \zeta) d \varepsilon=\sum_{i=1}^{k} w_{i} e^{\varepsilon_{i}} f\left(\varepsilon_{i}, \zeta\right) \ldots \ldots \\
& f\left(\varepsilon_{i}, \zeta\right)=\frac{y\left(q_{k}, \zeta\right) y\left(\varepsilon_{i}, \zeta\right)}{q_{k}{ }^{2}} ; \quad q_{k}=\left(x_{k}{ }^{3}-\varepsilon_{i}{ }^{3}\right)^{1 / 3} \ldots \\
& y\left(q_{k}, \zeta\right)=\sum_{i=1}^{n} \alpha_{i} e^{-q_{k}} \psi_{i-1}\left(q_{k}\right) \ldots \ldots \ldots \ldots
\end{aligned}
$$

therefore,

$$
\begin{gathered}
I x_{1}=w_{1} e^{\varepsilon_{1}} f\left(\varepsilon_{1}, \zeta\right) \\
I x_{2}=I x_{1}+w_{2} e^{\varepsilon_{2}} f\left(\varepsilon_{2}, \zeta\right) \\
I x_{n}=I x_{n-1}+w_{n} e^{\varepsilon_{n}} f\left(\varepsilon_{n}, \zeta\right)
\end{gathered}
$$

The term $I_{x}$ is given by:

$$
I_{x}=\int_{0}^{\infty} y(\varepsilon, \zeta) d \varepsilon=\sum_{i=1}^{n} w_{i} e^{\varepsilon_{i}} y\left(\varepsilon_{i}, \zeta\right) \ldots \ldots \ldots
$$

Since $\varepsilon_{i}$ are values of $x \leq x_{n}$, then in Equation (A.19) $\varepsilon_{i}$ are replaced by $x_{i}$

\section{Breakage rate}

The breakage rate, Equation (13), can be represented in matrix form as:

$$
B=B_{\text {con }}\left[\bar{Y}_{1}-\bar{Y}_{2}\right]
$$

where $B_{c o n}=k_{d} N_{o}\left(L_{c} d-1\right)$ and:

$$
\begin{aligned}
& \bar{Y}_{1}=2^{d / 3+1}\left[x_{1}^{d} y\left(1.26 x_{1}, \zeta\right) x_{2}^{d} y\left(1.26 x_{2}, \zeta\right) x_{3}^{d} y\left(1.26 x_{3}, \zeta\right)\right. \\
& \left.\ldots x_{n}^{d} y\left(1.26 x_{n} \zeta\right)\right]^{T} \\
& \bar{Y}_{2}=\left[x_{1}^{d} y\left(x_{1}, \zeta\right) x_{2}^{d} y\left(x_{2}, \zeta\right) x_{3}^{d} y\left(x_{3}, \zeta\right) \ldots x_{n}^{d} y\left(x_{n}, \zeta\right)\right]^{T}
\end{aligned}
$$

\section{NODE BY NODI CALCULATIONS}

The node points values of $\alpha_{i}\left(\zeta_{j}\right)$ at $x_{i} ; i=1,2, \ldots, n$ and $\zeta_{j}$; $j=1,2, \ldots, m$ are represented Equation (19). The second order ordinary differential equations can be transformed into a set of first order ordinary differential equations as:

$$
\bar{f}=\frac{d \bar{\alpha}}{d \zeta}
$$

$\bar{f}^{\prime}=\frac{d^{2} \alpha}{d \zeta^{2}}$

Therefore, Equation (19) becomes:

$$
\frac{d \bar{\alpha}}{d \zeta}=\bar{f}
$$

$$
\begin{gathered}
\frac{d \bar{f}}{d \zeta}-P e \bar{f}-P e \frac{G t_{m}}{L_{c}}\left(\overline{\bar{\Phi}}^{-1} \overline{\bar{T}}\right) \bar{\alpha}+P e \frac{L_{c} t_{m}}{N_{0}} \overline{\bar{\Phi}}^{-1}[\bar{A}+\bar{B}] \\
\quad=\overline{\bar{\Phi}}^{-1} \bar{R}(x, \zeta) \ldots \ldots \ldots \ldots \ldots \ldots \ldots \ldots \ldots \ldots \ldots \ldots \ldots \ldots \ldots
\end{gathered}
$$

Using Equation (8) interior node points along $x$ and one node point $\left(x_{1}\right)$ as the initial condition Equations (A.24) and (A.25) can be written in matrix form as:

$$
\left[\begin{array}{c}
\alpha_{1}^{\prime} \\
\alpha_{2}^{\prime} \\
\vdots \\
\alpha_{9}^{\prime}
\end{array}\right]=\left[\begin{array}{c}
I C \\
f_{1} \\
\vdots \\
f_{8}
\end{array}\right]
$$

$$
\begin{gathered}
{\left[\begin{array}{c}
f_{1}^{\prime} \\
f_{2}^{\prime} \\
\vdots \\
f_{8}^{\prime}
\end{array}\right]=P e\left[\begin{array}{c}
f_{1} \\
f_{2} \\
\vdots \\
f_{8}
\end{array}\right]+P e \frac{G t_{m}}{L_{c}}\left(\bar{\Phi}^{-1} \bar{T}\right)\left[\begin{array}{c}
\alpha_{2} \\
\alpha_{3} \\
\vdots \\
\alpha_{9}
\end{array}\right]} \\
-P e \frac{L_{c} t_{m}}{N_{0}} \overline{\bar{\Phi}}^{-1}(\bar{A}+\bar{B}) \ldots \ldots \ldots \ldots
\end{gathered}
$$

Therefore, a total of 17 first order ODE are to be solved (16 equations represent the interior nodes and 1 equation represents the initial condition). However, in order to solve Equation (A.26) we need to define the equation defined by $\alpha_{1}^{\prime}$, which is given by the IC (initial condition), so that we have a closed set of equations (17 equations and 17 unknowns; $8 \mathrm{f}$ 's and $9 \alpha$ 's). Substituting the approximate solution into the initial condition equation, Equation (20a), and taking the limit as the size $x_{k} \rightarrow 0$ gives:

$$
\sum_{i=1}^{n} \alpha_{i}(\zeta) \psi_{i-1}\left(x_{k}\right)_{x_{k} \rightarrow 0}-\frac{J / N_{0}}{G / L_{c}}=R_{k}(0, \zeta) ; x \rightarrow 0(0 \leq \zeta \leq 1)
$$

Differentiating once Equation (A.27) with respect to $\zeta$ gives:

$$
\begin{aligned}
& \alpha_{1}^{\prime} \psi_{0}(0)+\alpha_{2}^{\prime} \psi_{1}(0)+\alpha_{3}^{\prime} \psi_{2}(0)+\ldots+\alpha_{9}^{\prime} \psi_{8}(0) \\
& -\frac{d}{d \zeta}\left[\frac{J / N_{0}}{G / L_{c}}\right]_{x \rightarrow 0}=0 \ldots \ldots \ldots \ldots \ldots \ldots
\end{aligned}
$$


where:

$$
\frac{d}{d \zeta}\left[\frac{J / N_{o}}{G / L_{c}}\right]_{x \rightarrow 0}=\frac{J^{o} L_{c}\left(1-k_{B o} \zeta\right)^{a}}{G_{o}^{o} N_{o}\left(1-k_{G} \zeta\right)^{b}}\left[\frac{b k_{g}}{1-k_{g} \zeta}-\frac{a k_{B o}}{1-k_{B o} \zeta}\right]
$$

solving for $\alpha_{1}^{\prime}$ and substituting for $f$ results in:

$$
\alpha_{1}^{\prime}=\frac{1}{\psi_{0}(0)}\left\{\begin{array}{l}
\frac{J L_{c}\left(1-k_{B o} \zeta\right)^{a}}{G_{o}^{o} N_{o}\left(1-k_{C} \zeta\right)^{b}}\left[\frac{b k_{g}}{1-k_{g} \zeta}-\frac{a k_{B o}}{1-k_{B o} \zeta}\right] \\
-\left[f_{1} \psi_{1}(0)+f_{2} \psi_{2}(0)+\ldots+f_{8} \psi_{8}(0)\right]
\end{array}\right\}
$$

where $\psi_{o}(0)=1$. Therefore, now we have a closed system of equations. This set of 17 equations is solved at different values of $\zeta$. In this study, the number of node points along the $\zeta$ direction was 101 . This means a total of $101 \times 17$ first order ODEs are solved each time. The corresponding boundary condition at the entrance, $\zeta=0,1 / P e(\zeta) \rightarrow \infty$ (approaches mixed flow). Therefore the $\mathrm{BC}$ at the entrance can be simplified as:

$$
\bar{\alpha}=0 ; \quad \zeta=0(x>0)
$$

or if at any other starting location, then the boundary conditions corresponds to the PSD at that location. The boundary condition at the exit $\zeta=1$ is given by:

$$
\bar{f}=0 ; \quad \zeta=0(x>0)
$$

which means $\alpha_{i}$ 's are constant at the exit. For known PSD at the exit, $Y(x, 1)$, Equation (20c) can be integrated once to give:

$$
\bar{\alpha}=\overline{\bar{L}}^{-1} \bar{Y} ; \quad \zeta=1(x>0)
$$

This form of boundary condition was used during determination of kinetic parameters from the experimental data. In that case the values of $Y(x, \zeta)$ at the four sampling ports (different $\zeta$ ) are known.

\section{Acknowledgement}

The financial support provided by the Natural Sciences and Engineering Research Council of Canada is gratefully acknowledged.

\section{Nomenclature}

$a \quad=$ nucleation parameter

$A=$ net rate of population density change due to particle aggregation, $(\mathrm{no} / \mu \mathrm{m} \cdot \mathrm{mL} \cdot \mathrm{s})$

$A_{T}=$ total solids surface area per volume of solid free liquid, $\left(\mathrm{m}^{2} / \mathrm{m}^{3}\right)$

$b \quad=$ growth rate parameter

$B \quad=$ net rate of population density change due to particle breakage, $(\mathrm{no} / \mu \mathrm{m} \cdot \mathrm{mL} \cdot \mathrm{s})$

$B_{a} \quad=$ particle birth rate due to aggregation, $(\mathrm{no} / \mu \mathrm{m} \cdot \mathrm{mL} \cdot \mathrm{s})$

$B_{b} \quad=$ particle birth rate due to breakage, $(\mathrm{no} / \mu \mathrm{m} \cdot \mathrm{mL} \cdot \mathrm{s})$

$B_{c o n}=$ parameter defined in Equation (A.20)

$C^{c o n}=$ protein concentration, $\left(\mathrm{kg} / \mathrm{m}^{3}\right.$ of solid free liquid)

$\mathrm{Co}=$ protein concentration in the feed stream, $\left(\mathrm{kg} / \mathrm{m}^{3}\right)$

$C^{*} \quad=$ equilibrium protein concentration, $\left(\mathrm{kg} / \mathrm{m}^{3}\right)$
$C V \quad=$ experimental coefficient of variation based on volume distribution

$C V_{i j}=$ coefficient of variation based on volume distribution for run $i$ at jth port

$C V m_{i j}=$ calculated coefficient of variation based on volume distribution for run $i$ at $j$ th port

$d \quad=$ breakage parameter, Equation (10)

$d_{i j} \quad=$ mean particle size for run $i$ at $j$ th port, $\left(\mu \mathrm{m}^{4} / \mu \mathrm{m}^{3}\right)$

$d m_{i, j}=$ calculated mean particle size, $\left(\mu \mathrm{m}^{4} / \mu \mathrm{m}^{3}\right)$

$d_{i, j}=$ diameter of the tubular precipitator, $(\mathrm{cm})$

$D_{a} \quad=$ particle death rate due to aggregation, $(\mathrm{no} / \mu \mathrm{m} \cdot \mathrm{mL} \cdot \mathrm{s})$

$D_{b}^{a} \quad=$ particle death rate due to breakage, $(\mathrm{no} / \mu \mathrm{m} \cdot \mathrm{mL} \cdot \mathrm{s})$

$D_{z} \quad=$ axial dispersion coefficient, $\left(\mathrm{cm}^{2} / \mathrm{s}\right)$

$f^{z}=$ Fanning friction factor

$f(\varepsilon, \zeta)=$ function defined in Equation (A.16)

$F_{i j} \quad=$ frequency of orthokinetic collisions, Equation (1a)

$g=$ growth rate parameter, Equation (9a)

$G \quad=$ particle growth rate, $(\mu \mathrm{m} / \mathrm{s})$

$G_{a} \quad=$ aggregate growth rate, $(\mu \mathrm{m} / \mathrm{s})$

$G_{0}{ }^{o}{ }^{\circ} \quad=$ initial particle growth rate, $(\mu \mathrm{m} / \mathrm{s})$

$H \quad=$ objective equation to be minimized

IC = initial condition in Equation (A.26)

$l x_{k} \quad=$ function defined in Equation (A.18)

$l_{\infty} \quad=$ function defined in Equation (A.19)

$J \quad=$ nucleation rate, $(\mathrm{no} / \mathrm{mL} \cdot \mathrm{s})$

$J^{o}=$ initial nucleation rate, $(\mathrm{no} / \mathrm{mL} \cdot \mathrm{s})$

$k_{a} \quad=$ specific area shape factor

$k_{B}^{a}=$ nucleation parameter, Equation (8a)

$k_{B o}=$ nucleation parameter, Equation (8a)

$k_{d}=$ breakage rate parameter, Equation (10)

$k_{D} \quad=$ model parameter, death rate constant

$k_{E R}=$ constant, Equation (3c)

$k_{G} \quad=$ growth rate parameter, Equation (9a)

$k_{G o} \quad=$ growth rate parameter, Equation $(9 \mathrm{~b})$

$k_{m} \quad=$ nucleation parameter, Equation (8a)

$K_{e} \quad=$ model parameter, Equation (22)

$K_{e} \quad=$ model parameter, Equation (21)

$l_{I}{ }^{\prime}=$ location of measuring point I along the precipitator, $(\mathrm{cm}$ or $\mathrm{m}$ )

$L \quad=$ particle or aggregate size, $(\mu \mathrm{m})$

$L_{c} \quad=$ particle size scaling factor, $(=3.528 \mu \mathrm{m})$

$L_{i} \quad=$ particle or aggregate size at the ith channel or interval, $(\mu \mathrm{m})$

$L_{o} \quad=$ nuclei particle size, $(\mu \mathrm{m})$

$\stackrel{O}{T}_{T} \quad$ = solid protein concentration, $\left(\mathrm{kg} / \mathrm{m}^{3}\right.$ of solid free liquid)

$n \quad=$ number of node points used in approximation, Equation (16)

$=$ particle concentration, $(\mathrm{no} / \mathrm{mL})$

$=$ particle concentration in the size range $\mathrm{i},(\mathrm{no} / \mathrm{mL})$

$=$ population density scaling factor, $\left(=10^{5} \mathrm{no} / \mathrm{mL}\right)$

$=$ population density, $(\mathrm{no} / \mu \mathrm{m} \cdot \mathrm{mL})$

$=$ matrix of parameters to be optimized, Equation (23)

$=$ constant in Equations (15), (20) and (A.12)

$=$ Peclet number, $\left(l u / D_{z}\right)$

$=$ total liquid feed flow rate, $\left(\mathrm{m}^{3} / \mathrm{s}\right)$

= volumetric feed ratio, (precipitant/protein solution)

$=$ mean radius of particles in the size range $i,(\mu \mathrm{m})$

$=$ residual matrix, Equation (19)

$=$ aggregation rate, $($ no $/ \mu \mathrm{m} \cdot \mathrm{mL} \cdot \mathrm{s})$

$=$ regression coefficient

= supersaturation ratio

$=$ mean residence time, $(\mathrm{s})$

= matrix defined by Equation (A.10)

= superficial liquid velocity, $(\mathrm{cm} / \mathrm{s})$

$=$ superficial liquid velocity, $(\mathrm{cm} / \mathrm{s})$

$=$ total volume fraction of particles at the ith channel or interval

$\begin{array}{ll}V & =\text { precipitator volume, }(\mathrm{mL}) \\ w_{i} & =\text { weighting factors of Gaussian-Laguerre quadrature, }\end{array}$ Equation (A.11)

$W \quad=$ solid protein concentrations, $\left(\mathrm{kg} / \mathrm{m}^{3}\right.$ of solid free liquid $)$ 
= dimensionless length along the tubular precipitator, Equation (5)

$=n$ zeros of the Laguerre polynomial

$=$ dimensionless population density, Equation (5)

$=$ matrix of $y$, Equation (A.2)

$=$ precipitator length, $(\mathrm{cm}, \mathrm{m})$

$=$ total length of the precipitator, $(\mathrm{cm}, \mathrm{m})$

\section{Greek letters}

$\alpha_{i} \quad=$ weighting parameter in Equation (16)

$\alpha=$ matrix of $\alpha_{i}$, Equation (A.3)

$\beta=$ aggregation kernel in Equation $(14),(\mathrm{mL} / \mathrm{s})$

$\beta_{1}=$ constant aggregation kernel, $(\mathrm{mL} / \mathrm{s})$

$\gamma_{i k}=$ elements of matrix, Equation (33)

$\delta_{i j}=$ Kronecker delta, $\left(\delta_{i j}=0\right.$ if $i \neq j ;=1$ if $\left.i=j\right)$

$\zeta=$ dimensionless particle size

$\varepsilon . \quad=$ dimensionless particle size less than $x$, Equation (A.15)

$\eta \quad=$ rate of energy dissipation per unit mass, $(\mathrm{W} / \mathrm{kg})$

$\Lambda_{i j} \quad=$ variable in Equations (lb) and (lc)

$\mu_{i} \quad=$ model parameter in Equation (22)

$\mu_{0}=$ model parameter in Equation (21)

v $=$ kinematic viscosity of liquid, $\left(\mathrm{m}^{2} / \mathrm{s}\right)$

v) = kinematic viscosity of liquid, $\left(\mathrm{m}^{2} / \mathrm{s}\right)$

$\sigma \quad=$ apparent relative supersaturation

$\tau=$ mean residence time of solid-free liquid, (s)

$\Phi_{i} \quad=$ function defined in Equation (17)

$\Phi^{\prime} \quad=$ matrix defined in Equation (A.4)

$\phi_{i, k}=$ elements of matrix Equation (A.4)

$\psi_{i}=$ ith term in Laguerre polynomial, Equation (17)

\section{Abbreviations}

MSM $=$ multiple shooting method

$M W R=$ method of weighted residue

$O C M=$ orthogonal collation method

$\mathrm{PBE}=$ population balance equation

PSD = particle size distribution

SAM = simulated annealing method

\section{References}

Ascher, U., R. Mattheij and R. D. Russel, "Numerical Solution of Boundary Value Problem for Ordinary Differential Equation", Prentice-Hall Inc. New York, NY (1988) p. 157.

Bhatia, S. K. and D. Chakraborty, "Modified MWR Approach: Application to Agglomerative Precipitation", AIChE J. 38, 868-878 (1992).

Brown, D. L. and C. E. Glatz, "Aggregate Breakage in Protein Precipitation," Chem. Eng. Sci. 42, 1831-1839 (1987).

Chan, M. Y. Y., M. Hoare, and P. Dunnill, "The Kinetics of Protein Precipitation by Different Reagents", Biotechnol. Bioeng. 28, 387-393 (1986).

Chang, R. and M. Wang, "Modelling the Batch Crystallization Process via Shifted Legendre Polynomials", Ind. Eng.. Chem. Process Des. Dev. 23, 463-468 (1984).

Chen, M. and S. Rohani, "Recovery of Canola Meal Protein by Precipitation", Biotechnol. Bioeng. 40, 63-68 (1992).

Courant, R. and D. Hilbert, "Methods of Mathematical Physics", Vol. 1, 7th edition, Wiley Interscience, New York, NY (1966).

Finlayson, B. A., "The Method of Weighted Residuals and Variational Principles", Academic Press, New York, NY (1972).

Glatz, C. E., M. Hoare and J. LandaVertiz, "The Formation and Growth of Protein Precipitates in a Continuous Stirred Tank Reactor", AIChE J. 32, 1196-1204 (1986).

Grabenbauer, G. C. and C. E. Glatz, "Protein PrecipitationAnalysis of Particle Size Distribution and Kinetics", Chem. Eng. Commun. 12, 203-219 (1981).

Goffe, B., Ferrier and Rogers, "Global Optimization of Statistical Functions With Simulated Annealing", J. Econometrics 60, $65-100(1994)$.
Gupta, B. S. and T. K. Dutta, "Monte Carlo Simulation of Transient CSD in a Continuous Crystallizer", Chem. Eng. Technology 13, 392397 (1990).

Hindmarsh, A. C., "LSODE and LSODI, Two New Initial Value Ordinary Differential Equation Solvers", ACM SIGNUM Newsletter, December (1980).

Hounslow, M. J., R. L. Ryall and V. R. Marshall, "A Discretized Population Balance for nucleation, Growth, and Aggregation", AIChE J. 34, 1821-1832 (1988).

Hounslow, M. J., "A Discretized Population Balance for a Continuous System at Steady State", AIChE J. 36, 106-116 (1990a).

Hounslow, M. J., "Nucleation, Growth, and Aggregation Rates From Steady State Experimental Data", AIChE J. 36, 1748-1752 (1990b).

Hulburt, H. M. and S. Katz, "Some Problems in Particle Technology A Statistical Mechanical Formulation", Chem. Eng. Sci. 19, 555-574 (1964).

Kim, W.-S. and J. M. Tarbell, "Numerical Technique for Solving Population Balances in Precipitation Processes", Chem. Eng. Comm. 101, 115-129 (1991).

Kinsella, J. E, J.Am. Oil Chem. Soc. 56, 242 (1979).

Lakatos, B., E. Varga, S. Halasz and T. Blickle, "Simulation of Batch Crystallizers" Industrial crystallization", 84, edited by S. J. Jancic and E. J. de Jong, Elsevier Science Publishers B. V. Amsterdam, The Netherlands 185-190 (1984).

Levenspiel, O., "Chemical Reaction Engineering", $2^{\text {nd }}$ edition, Wiley, New York, NY (1972).

Lister, J. D., D. J. Smit and M. J. Hounslow, "Adjustable Discretized Population Balance for Growth and Aggregation", AIChE J. 41, 591-603 (1995).

Machall, P., R. David, J. P. Klein and J. Villermaux, "Crystallization and Precipitation Engineering I. An Efficient Method for Solving Population Balance in Crystallization With Agglomeration", Chem. Eng. Sci. 43, 59-67 (1988).

Mullin, J. W., "Crystallization", 2nd ed, Buterworths, London, UK (1972).

Nauman, E. B. and B. A. Buffham, Mixing in Continuous Flow Systems, Wiley, New York, NY (1983).

Nelson, C. D. and C. E. Glatz, "Primary Particle Formation in Protein Precipitation”, Biotechnol. Bioeng. 27, 1434-1444 (1985).

Padia, B. K. and S. K. Bhatia, "Multiplicity and Stability Analysis of Agglomeration Controlled Precipitation", Chem. Eng. Commun. 104, 227-244 (1991).

Petenate, A. M. and C. E. Glatz, "Isoelectric Precipitation of Soy Protein", I. Factor Affecting Particle Size Distribution", Biotechnol. Bioeng. 25, 3049-3058 (1983a).

Petenate, A. M. and C. E. Glatz, "Isoelectric Precipitation of Soy Protein", II. Kinetics of Protein Aggregate Growth and Breakage", Biotechnol. Bioeng. 25, 3059-3078 (1983b).

Randolph, A. D. and M. A. Larson, "Theory of Particulate Processes", 2nd Edition, Academic Press, New York, NY (1988).

Raphael, M., S. Rohani and F. Sosulski, "Isoelectric Precipitation of Sunflower Protein in a Tubular Precipitator", Can. J. Chem. Eng. 73, 470-483 (1995).

Raphael, M. and S. Rohani, "Isoelectric Precipitation of Sunflower Protein in an MSMPR Precipitator: Modelling of PSD With Aggregation", Chem. Eng. Sci. 51, $4379-4384$ (1996a).

Raphael, M. and S. Rohani, "On-line Estimation of Solids Concentrations and Mean Particle Size Using a Turbidimetry Method", Powder Technology 89, 157-163 (1996b).

Rawlings, J. B., W. R. Witkowski and J. W. Eaton, "Modelling and Control of Crystallizers", Powder Technology 69, 39 (1992).

Rivera, T. and A. D. Randolph, "Model for the Precipitation of Pentaerythritol Tetranitrate", Ind. Eng. Chem. Process Des. Dev. 17, 182188 (1978).

Rohani, S. and M. Chen, "Aggregation and Precipitation Kinetics of Canola Protein by Isoelectric Precipitation", Can. J. Chem. Eng. 71, 689-698 (1993). 
SAS User's Guide: Statistics, SAS Institute Inc., $5^{\text {th }}$ ed., Cary, NC (1985).

Saleeby, E. G. and H. W. Lee, "Solution and Analysis for Crystallization With Agglomeration", Chem. Eng. Sci. 49, 1879-1884 (1994).

Sampson, K. J. and D. Ramkrishna, "A New Solution to the Brownian Coagulation Equation Through the Use of Root Shifted Problem Specific Polynomials", J. Colloid Interface Sci. 103, 245-254 (1985).

Singh, P. N. and D. Ramkrishna, "Transient Solution of Brownian Coagulation Equation by ProblemSpecific Polynomials", J. Colloid Interface Sci. 53, 214-223 (1975).

Singh P. N and D. Ramkrishna, "Solution of Population Balance Equation by MWR", Computer and Chemical Engineering 1, 23-31 (1977).

Subramanian, G. and D. Ramkrishna, "On the Solution of Statistical Models of Cell Populations", Mathematical Biosciences 10, 123 (1971).
Tavare, N. S. and J. Garside, "Multiplicity in Continuous MSMPR Crystallizers in an lsothermal crystallizer", AIChE J. 31, 1121 (1985).

Twineham, M., M. Hoare and D. J. Bell, "The Effects of Protein Concentration on the Breakup of Protein Precipitate by Exposure to Shear", Chem. Eng. Sci. 39, 509-513 (1984).

Villadsen, J. and M. L. Michelsen, "Solutions of Differential Equation Models by Polynomial Approximation", Prentice Hall, Engelwood Cliffs, NJ (1978).

Virkar, P. D., M. Hoare, M. Y. Y. Chan and P. Dunnill, "Kinetics of the Acid Precipitation of Soya Protein in a Continuousflow Tubular Reactor", Biotechnol. Bioeng. 24, 871-887 (1982).

Witkowski, W. R. and J. B. Rawlings, "Modelling and Control of Crystallizers", Proc. 1987, American Control Conf., Minneapolis. MN, 1400-1405, June 1987.

Manuscript received May 13, 1998; revised manuscript received January 27, 1999; accepted for publication March 23, 1999. 